\title{
Moral HaZARD IN High OFFICE AND the DyNAMICS OF ARISTOCRACY
}

by Roger B. Myerson

October 2008, revised June 2015

http://home.uchicago.edu/ rmyerson/research/power.pdf

Abstract: Both aristocratic privileges and constitutional constraints in traditional monarchies can be derived from a ruler's incentive to minimize expected costs of moral-hazard rents for high officials. We consider a dynamic moral-hazard model of governors serving a sovereign prince, who must deter them from rebellion and hidden corruption which could cause costly crises. To minimize costs, a governor's rewards for good performance should be deferred up to the maximal credit that the prince can be trusted to pay. In the long run, we find that high officials can become an entrenched aristocracy with low turnover and large claims on the ruler. Dismissals for bad performance should be randomized to avoid inciting rebellions, but the prince can profit from reselling vacant offices, and so his decisions to dismiss high officials require institutionalized monitoring. A soft budget constraint that forgives losses for low-credit governors can become efficient when costs of corruption are low.

Keywords: moral-hazard rents, foundations of the state, minimizing turnover, soft budget constraint

Address: Economics Dept., University of Chicago, 1126 East 59th Street, Chicago, IL 60637, USA.

Phone: 773-834-9071. Fax: 773-702-8490.

Email: myerson@uchicago.edu.

Home page: http://home.uchicago.edu/ rmyerson/

Acknowledgment: The author is indebted to Konstantin Sonin for many comments on this paper. Computations: All computations in this paper can be done in a spreadsheet available at http://home. uchicago.edu/ rmyerson/research/prince.xls 


\section{Moral HaZARD In High OFFICE AND THE DyNAMICS OF ARISTOCRACY \\ by Roger B. Myerson}

\section{Introduction.}

Dynamic moral-hazard models offer economic insights into the problems of maintaining long-term trust of agents who exercise delegated power in a relationship or organization. Becker and Stigler (1974), after noting that reliable law enforcement was regularly taken for granted as an essential assumption in economic analysis, formulated a model of dynamic moral hazard to analyze how government officials could be efficiently motivated to enforce laws. Since then, many models of dynamic moral hazard have been studied in economic theory, because problems of trust are fundamental to every institution in society.

Moral-hazard agency theory begins with the basic observation that, in positions that offer opportunities for profitable abuse of power, agents must be motivated to behave appropriately by expectations of better rewards for good performance. When alternative outcomes for bad performance are bounded below by agents' ability to evade penalties (limited liability), the required rewards for good performance may be more than what agents would demand simply to accept the position. Thus, agents who hold such responsible positions must be promised surplus rewards, called moral-hazard rents. In dynamic moral-hazard problems, the costs of moralhazard rents can be reduced by postponing substantial rewards until late in agents' careers, because the prospect of a late-career reward for good long-term performance can motive good behavior throughout an agent's career. Becker and Stigler suggested that the net cost of such incentives could be further reduced if, before taking the position, an agent could be required to make some initial payment for the expected benefits that the position will entail.

These basic observations of moral-hazard agency theory have fundamental implications for any organization that delegates substantial powers to responsible agents. The savings from deferring moral-hazard rents can be realized only if agents in responsible positions expect longterm careers in the organization. Thus, an efficient incentive plan should minimize turnover in positions of power. However, long-term promises of deferred rewards become costly debts of the organization, and the organization could subsequently profit from denying such debts if its future credit would not be harmed. Thus, like any creditors, the responsible agents of an organization need some mechanism to enforce their claims. 
Among the organizations of society that delegate power to responsible officials, none is more important than government. High government officials regularly hold wide powers that could be profitably abused. So the moral-hazard agency theory should have fundamental applications for understanding the structures of political systems throughout history. This paper develops a simple dynamic moral-hazard model to try to highlight some basic implications of agency theory for political science.

In an agency model of government, moral-hazard rents become benefits of a privileged political elite. The advantages of minimizing turnover, to reduce the expected cost of such rents, suggests that efficient political organizations may tend to minimize future entry into the political elite, which may then become an entrenched aristocracy. However, the need for mechanisms to guarantee the long-term allocation of moral-hazard rents in government can be a fundamental force for the development of political institutions that constrain rulers and regulate the allocation of power. Thus, an agency model of government may offer insights into both the dynamics of aristocratic privilege and the foundations of constitutional government.

An economic theory of elite privileges does not have to be an apology for them. If we would reduce political inequality in a good society then we need to understand the economic forces that have made such inequality so common throughout history. But here, even as our theory finds forces for long-term privileges of a political elite, it also finds forces for constitutional government and institutions of law. Indeed, the historical development of modern democracy has been based on such institutions, whose function was gradually extended from guaranteeing the allocation of aristocratic privileges to protecting the rights of all citizens.

For example, among the early roots of the Western political institutions that forged the modern world, the Court of the Exchequer stands out from the twelfth century as the central institution underlying the growth of royal power in medieval England (Warren, 1973, ch 6-8; FitzNigel, 1983). The Exchequer maintained accounts of the king's transactions with his sheriffs, who were the primary agents of royal power in the counties of England. But the rules and procedures of the Exchequer required that the sheriffs' transactions must be witnessed in detail by a panel of high officials and barons of the Exchequer. The Court of the Exchequer was designed so that, if the king needed to punish one of his sheriffs for malfeasance, a broad group of high officials could certify the grounds for such punishment. Thus, this institution served to maintain the basis for trust between powerful agents of local government and high officials of the central 
government.

Institutions with similar functions can be found in successful political systems throughout history. In ancient Rome, the Senate was an institutional forum where rights of senior government officials could be protected. As early as $1500 \mathrm{BCE}$, the Hittite king Telipinu created a similar institutional structure. To end conflict among his royal relatives who governed the provinces of the Hittite empire, Telipinu constrained himself with a new constitutional rule: that the king should never punish any member of the royal family without a formal trial before the assembled royal council or Panku (van den Hout, 1997, Beckman, 1982). So this ancient Hittite council, like the medieval Exchequer, was an institution designed to help maintain trust between the king and those on whom he relied as the regional agents of state power.

Our understanding of government is incomplete if we do not recognize why such institutions should be so important in the foundations of the state. The model of this paper is intended to highlight the basic agency problem that these institutions can help to solve.

In a previous paper (Myerson, 2008), I considered a different model, which focused on the problem of binding a sovereign political leader to fulfill his promises to reward the supporters who helped him win power. Initial supporters must be motivated by expectation of future rewards if they win. A leader who would be an absolute monarch would have difficulty recruiting support to win power if nothing could constrain him to fulfill past promises when his rivals have been defeated. Myerson (2008) showed that, in negotiation-proof equilibria of a model of sequential contests for power, a contender for power can recruit a competitive force of supporters only by organizing them into a group that could depose him if he cheated any one of them. Thus, a leader's need to raise a competitive army of supporters to win power is itself a fundamental force for constitutional constraints in government.

Here we derive a similar conclusion, but where Myerson (2008) focused on a political leader's need for trust of supporters (captains) in winning power, this paper here focuses on a ruler's need for trust of high officials (governors) in wielding power. The state's captains and governors are like a firm's investors and managers: all need some institutional protection for their promised future rewards.

The principal-agent model that we consider here is a simple variant of standard dynamic moral-hazard models in the literature, with the principal interpreted here as an established political leader or prince, and the agent interpreted as a powerful government official or 
governor. Our main results depend on several distinguishing features of our model.

First, we drop the common assumption that an agent can guarantee herself a good record by good behavior. Thus, under an incentive plan that can deter corrupt abuse of power, officials who have served correctly may nevertheless have bad outcomes and so must face a positive probability of being denied the promised rewards that motivated their good behavior.

Second, we assume that job candidates can pay some positive amount for promotion to a valuable high office but do not have sufficient funds to pay the full expected value of their promotion. When new officials cannot pay for the full value of the bonuses that they will expect in office, the leader's ex ante expected net cost is minimized by promising an employment policy that minimizes the expected turnover of his officials. But when new officials can pay some positive amount for their promotion to office, the leader actually profits ex post whenever he dismisses an official without rewards and promotes a new candidate. Thus, an effective leader may need to commit himself by creating institutions that constrain and regulate his ability to opportunistically dismiss officials.

Third, in addition to the possibility of hidden corruption by officials, we admit a second way that they can abuse their power, by open rebellion, which could become optimal for them if they knew that they were about to be punished. The need to deter both hidden corruption and open rebellion here compels the leader to use a randomized strategy in judging high officials when they have bad outcomes. But others cannot verify that such a randomized judgment strategy has been implemented correctly without directly monitoring the process by which the judgment has been determined. This result is significant because a formal trial in an institutionalized court is, in essence, a judicial process that is designed for such monitoring.

Fourth, to introduce limits on the credibility of the leader's promises in the simplest possible way (without introducing multilateral game-theoretic complexity into our principalagent problem), we add a parametric bound on the value of the deferred compensation that the leader can be trusted to owe any one official. We show that raising this bound always improves the leader's ex ante expected value but can ultimately reduce the expected turnover rate toward zero. Thus, a high trust bound implies that, in the long run, high officials will become entrenched in office and will accumulate large expensive claims on the state's resources.

For computational tractability, we analyze here a continuous-time Poisson agency model. However, to clarify the methodological basis for this analysis, we explicitly derive our results for 
this continuous-time agency model from limits of discrete-time agency models.

The basic structure of our dynamic agency model is introduced in section 2 below. The optimal solution for the discrete-time version of the model is characterized in section 3 , and the continuous-time limit is derived in section 4. Section 5 characterizes the steady-state distribution of outcomes of this optimal incentive plan that would result in the long run from applying it to many high offices. Other interpretive aspects of the solution are considered in section 6 .

While most of this paper assumes that the incentive plan must deter high officials from corruption, section 7 admits the possibility of tolerating some corruption, which will require us to take account of its potential costs for the leader. When the expected costs of corruption would be high, the analysis of section 7 justifies the assumptions of the previous sections. In other cases, however, we find that low credit bounds can cause soft budget constraints to become optimal for the leader, so that governors' losses may be forgiven and their corruption may be tolerated when their credit is low.

Other possible assumptions about the circle of trust around a political leader are discussed in section 8, and section 9 summarizes conclusions from our analysis. Mathematical proofs of the main results are collected in section 10 .

As noted above, the model here is a simple variant of standard dynamic moral-hazard models in the literature going back to Becker and Stigler (1974), Lazear (1981), Shapiro and Stiglitz (1984), and Akerlof and Katz (1989). Ray (2002) offers a general characterization of conditions for efficient dynamic incentive plans to back-load an agent's rewards (see also Thomas and Worrall, 2010). Bounds on the agent's ability to make initial payments to the principal are essential for these results, as is shown by the alternative stationarity results of Levin (2003) (see also Fong and Li, 2012).

Biais, Marriotti, Rochet, and Villeneuve (2010) have a recent model that is particularly close to ours, but where they prevent infinite back-loading of an agent's rewards by assuming that the agent is less patient than the principal, here we instead introduce a credit bound on what principal can credibly promise the agent. Abreu, Milgrom and Pearce (1991), Macleod (2007), and Sannikov and Skrzypacz (2010) have also studied models where agents must be motivated to minimize crises that occur as Poisson process whose rate depends on hidden effort variables. Our soft budget constraint results in section 7 here are similar to what Zhu (2013) has independently found for a model where an agent controls the drift of a Brownian motion. 
Implications of agency theory for political science have been explored by others since Barro (1973) and Ferejohn (1986); for a broad overview see Besley (2006). Adverse selection problems in relationships between rulers and powerful ministers have been analyzed by Egorov and Sonin (2011). Other recent models of agency in politics include Acemoglu, Robinson, and Verdier (2004), Padro-Miquel (2007), Acemoglu, Golosov, and Tsyvinski (2008), Debs (2010), and Padro-i-Miquel and Yared (2012).

\section{A dynamic agency model of governors}

To analyze the problems of motivating high government officials, we consider a dynamic agency model in which a high official, whom we may call a governor, serves under a political leader, whom we may call the prince. For clarity, we use female pronouns for governors and male pronouns for the prince. At any point in continuous time, the governor has three options: she may serve correctly as a good governor, or she may act corruptly, or she may openly rebel. The option of rebellion may also be interpreted as intensively looting the province and then fleeing abroad with the resulting treasures. We let $\mathrm{D}$ denote the expected total payoff to a governor when she rebels. The prince could observe any such rebellion.

The governor's choice among her other two alternatives, of good service or corruption, cannot be directly observed by the prince, but the prince can observe certain crises that may occur in the governor's province. When the governor serves correctly, crises will occur in her province as a Poisson process with rate $\alpha$. On the other hand, when the governor acts corruptly, crises will occur in her province as a Poisson process with rate $\beta$, and the corrupt governor will also gain an additional secret income worth $\gamma$ per unit time. That is, in any short time interval of length $\varepsilon$, if the governor is serving correctly then the probability of a crisis during this interval is $1-\mathrm{e}^{-\alpha \varepsilon} \approx$ $\alpha \varepsilon$; but if the governor is acting corruptly then the probability of a crisis during this interval is $1-\mathrm{e}^{-\beta \varepsilon} \approx \beta \varepsilon$, and the corrupt governor would get an additional secret income worth $\gamma \varepsilon$ during this interval. We assume that $\beta>\alpha$.

We assume that the governor observes any crisis in her province shortly before the prince observes it. After any crisis, the governor can make a short visit to the prince's court, and the governor cannot rebel during such a short visit. The lengths of these short intervals may be considered as infinitesimals in our continuous-time model.

The possibility of profiting from rebellion or corruption can make the office of governor 
very valuable. The moral hazard-rents of the office, which the prince must pay to deter such misbehavior, are the surplus above the alternative that a candidate could expect out of office (which we may normalize to 0 ). To minimize net costs, the prince would not give away an office when equally good candidates would pay for it. But we assume that all candidates for promotion to governor have limited wealth, which is denoted by K. (If governors could prepay the prince for all expected moral-hazard rents then the prince would have no reason to minimize them by back-loading rewards; see Levin, 2003.) We assume that the potential profit for a rebellious governor is strictly greater than what any candidate could pay for the office; that is, $\mathrm{K}<\mathrm{D}$.

We assume (until section 7) that the prince's regime would suffer a large expected cost from any crisis or rebellion, and so the prince wants to always deter governors from rebellion or corruption. So we seek an incentive plan that make a governor always prefer to serve correctly.

We assume that each individual is risk neutral and discounts future payments at the rate $\delta$ per unit time. Thus, we can analyze this agency problem with a recursive model in which the overall payoffs for the prince and governor are the sum of the payments that they get in some short time period, plus the expected present discounted value of all their future payments after this period. (See for example Abreu, Pearce, and Stacchetti, 1990.) At any point in time, the governor's expected discounted value of future payments may be called the governor's credit, and it effectively summarizes the quality of the governor's expected future relationship with the prince after this point in time.

The governor's credit is a debt owed by the prince. The prince can derive some advantage from deferring payments to a governor, but the prince's temptation to sack a governor will increase with the debt that is owed to her. To describe the bounds on trust of the prince, we let $\mathrm{H}$ denote the largest credit owed to a governor that the prince could be trusted to pay. If the prince's debt to a governor ever became larger than $\mathrm{H}$, then the prince would abuse his own power to eliminate the governor and the debt.

Thus, our simple model is characterized by the seven parameters $(\mathrm{D}, \alpha, \beta, \gamma, \mathrm{K}, \mathrm{H}, \delta)$, which are all assumed to be positive numbers. In section 7 we will introduce a parameter $L$ to denote the prince's cost from any crisis, but for now we may simply assume that this cost is sufficiently large that the prince will always want to deter corruption, to keep the expected cost of crises always constant at its minimal value ( $\alpha \mathrm{L}$ per unit time). 


\section{A discrete-time model}

Our continuous-time model can be formally understood as the limit of a discrete-time model, where each period is separated from the next by a short interval of time $\varepsilon$. The basic principles of analysis can be clarified by considering a discrete-time model first, but its solutions become easier to compute numerically in the limit as the time interval $\varepsilon$ goes to 0 . So in this section we formulate our discrete-time model, and then we characterize the continuous-time limit of its solutions in the next section.

In our discrete-time model, each period has a sequence of four stages. First, the governor can make a short visit to the prince's court, where the governor may be paid some amount cy and may be dismissed with some probability q. If the governor were dismissed then a new candidate would pay $\mathrm{K}$ to the prince to be appointed as the new governor. Second, the governor decides between serving correctly or acting corruptly. If she acts corruptly then she takes the corrupt income $\varepsilon \gamma$. Third, an observable crisis occurs with probability $\varepsilon \alpha$ if the governor is serving correctly but with probability $\varepsilon \beta$ if the governor is acting corruptly. Fourth, after observing whether there is a crisis or not, the governor decides whether to rebel or not. If she rebels, then the governor takes the terminal payoff $\mathrm{D}$ and exits the game. Otherwise, at the end of the period, the prince's incentive plan should implicitly promise the governor some future credit, the expected discounted value of her future payoffs, which may depend on whether a crisis has occurred or not. Let $r$ denote the governor's expected future credit if a crisis did not occur this period, but let $\mathrm{r}-\mathrm{z}$ denote the expected discounted value of the governor's future payoffs if a crisis occurred this period. That is, $\mathrm{z}$ here denotes the amount by which the governor's promised future credit would be reduced by a crisis this period. In each period, the expected pay rate y and the probability of dismissal $\mathrm{q}$, and the future-credits amounts $\mathrm{r}$ and $\mathrm{z}$ are decision variables to be chosen by the prince as a function of the past history.

To recursively formulate one period of this discrete-time model, let the parameter $u$ denote the credit that was promised to the incumbent governor at the end of the previous period. Given the past credit $u$ (which may depend on the entire past history), the decision variables $(\mathrm{y}, \mathrm{q}, \mathrm{r}, \mathrm{z})$ in this period can be chosen by the prince subject to several constraints. For this period's pay and future credit to fulfill the promise of credit $u$ from the previous period, when the governor serves correctly, the promise-keeping constraint is

$$
\varepsilon y+(1-q)[(1-\varepsilon \alpha) r+\varepsilon \alpha(r-z)] \geq(1+\varepsilon \delta) u .
$$


Here $1 /(1+\varepsilon \delta)$ is the discount factor for one period in this discrete-time model. If dismissed, the former governor would get 0 thereafter. The inequality in the constraint (1) represents an assumption that the prince could always reduce a governor's utility by unproductive punishment, which could be applied if the left side were strictly larger than the amount required on the right.

To deter the governor from behaving corruptly, the no-corruption incentive constraint is

$$
(1-\varepsilon \alpha) \mathrm{r}+\varepsilon \alpha(\mathrm{r}-\mathrm{z}) \geq \varepsilon \gamma+(1-\varepsilon \beta) \mathrm{r}+\varepsilon \beta(\mathrm{r}-\mathrm{z}) .
$$

This constraint says that the corrupt income $\varepsilon \gamma$ is not worthwhile for the governor when she takes account of the increased probability $\varepsilon(\beta-\alpha)$ of suffering the crisis penalty is z. Constraint (2) is equivalent to $\mathrm{z} \geq \gamma /(\beta-\alpha)$. Let $\tau$ denote this minimal deterrent penalty

$$
\tau=\gamma /(\beta-\alpha) \text {. }
$$

Then the no-corruption constraint (2) can be rewritten equivalently:

$$
\mathrm{Z} \geq \tau \text {. }
$$

To deter rebellion after a crisis, the no-rebellion incentive constraint is

$$
\mathrm{r}-\mathrm{z} \geq \mathrm{D} \text {. }
$$

As the penalty z must be nonnegative, from $\left(2^{\prime}\right)$, this constraint also implies that the governor would not want to rebel in a period when there has not been a crisis.

The upper bound on how much the prince can credibly promise is

$$
\mathrm{r} \leq \mathrm{H} .
$$

Finally, we have nonnegativity constraints on the governor's wage rate y (as she already paid her endowment $\mathrm{K}$ for the appointment) and for the dismissal probability q:

$$
\mathrm{y} \geq 0,0 \leq \mathrm{q} \leq 1 .
$$

Constraints (2)-(3) together imply that, in a period when there is no corruption, the governor's future credit $r$ cannot be less than $\mathrm{D}+\tau$. Let $\mathrm{G}$ denote this minimal non-crisis credit:

$$
\mathrm{G}=\mathrm{D}+\tau=\mathrm{D}+\gamma /(\beta-\alpha) .
$$

So constraints (2)-(4) require that the given parameters must satisfy

$$
\mathrm{H} \geq \mathrm{G} \text {. }
$$

A feasible incentive plan characterizes how these decision variables should be chosen by the prince as a function of the past credit $\mathrm{u}$

$$
(\mathrm{y}, \mathrm{q}, \mathrm{r}, \mathrm{z})=(\mathrm{y}(\mathrm{u}), \mathrm{q}(\mathrm{u}), \mathrm{r}(\mathrm{u}), \mathrm{z}(\mathrm{u}))
$$

subject to (1)-(5) for all possible credit levels u between the rebellion threshold D and the trust bound $\mathrm{H}$. 
Now we can recursively characterize the prince's value function. Let $\mathrm{v}_{0}$ denote the prince's minimal expected discounted value of future costs when a new governor is appointed. Let $\mathrm{V}(\mathrm{u})$ denote the prince's minimal expected discounted value of future costs at the end of a period when the incumbent governor expects credit $u$. So the prince's optimal expected value when a new governor is appointed must satisfy the initial equation

$$
\begin{aligned}
& \mathrm{v}_{0}=\operatorname{minimum}_{\mathrm{y}, \mathrm{r}, \mathrm{z}}-\mathrm{K}+\varepsilon \mathrm{y}+(1-\varepsilon \alpha) \mathrm{V}(\mathrm{r})+\varepsilon \alpha \mathrm{V}(\mathrm{r}-\mathrm{z}) \\
& \text { subject to }(2)-(5) .
\end{aligned}
$$

Here the initial $-\mathrm{K}$ represents the payment from the new governor, which is a negative cost. Then for any credit $u$ that the governor could expect at the end of any period, the prince's expected discounted future value $\mathrm{V}(\mathrm{u})$ must satisfy the recursion equation

$$
\begin{aligned}
& \mathrm{V}(\mathrm{u})=\operatorname{minimum}_{\mathrm{y}, \mathrm{q}, \mathrm{r}, \mathrm{z}}\left\{\varepsilon \mathrm{y}+\mathrm{qv}_{0}+(1-\mathrm{q})[(1-\varepsilon \alpha) \mathrm{V}(\mathrm{r})+\varepsilon \alpha \mathrm{V}(\mathrm{r}-\mathrm{z})]\right\} /(1+\varepsilon \delta) \\
& \text { subject to (1)-(5). }
\end{aligned}
$$

These recursive optimality conditions (6) and (7), for all $u$ in the interval $[\mathrm{D}, \mathrm{H}]$ determine the value function $\mathrm{V}$ and the optimal solution for this discrete-time model.

Constraints (2)-(4) imply $r-z \geq D=G-\tau$ and $r \geq G$, and so the governor's expected end-of-period credit $(1-\varepsilon \alpha) r+\varepsilon \alpha(r-z)$ cannot be less than $\mathrm{G}-\varepsilon \alpha \tau$, which would correspond to $(\mathrm{G}-\varepsilon \alpha \tau) /(1+\varepsilon \delta)$ in the previous period. Let us denote this amount by $\mathrm{G}_{\varepsilon}$ :

$$
\mathrm{G}_{\varepsilon}=(\mathrm{G}-\varepsilon \alpha \tau) /(1+\varepsilon \delta) .
$$

Before a period where there is no chance of punishment or dismissal, the governor's expected future credit would have to be at least $\mathrm{G}_{\varepsilon}$. It will also be useful to define $\mathrm{H}_{\varepsilon}=(\mathrm{H}-\varepsilon \alpha \tau) /(1+\varepsilon \delta)$. We assume that the time interval $\varepsilon$ is small enough that

$$
\tau>\varepsilon(\delta \mathrm{H}+\alpha \tau) .
$$

This implies $\tau-\varepsilon \alpha \tau>\varepsilon \delta \mathrm{H}$, and so $\mathrm{G}-\varepsilon \alpha \tau>(1+\varepsilon \delta) \mathrm{D}>\mathrm{K}$ and $\mathrm{G}_{\varepsilon}>\mathrm{D}$.

The optimal discrete-time solution is characterized by the following theorem, which is proven in section 10 .

Theorem 1. In the discrete-time model with short period length $\varepsilon$, the value function $\mathrm{V}(\mathrm{u})$ is an increasing convex function of $\mathrm{u}$ in the interval $[\mathrm{D}, \mathrm{H}]$, and its slope $\mathrm{V}^{\prime}(\mathrm{u})$ is always between $\mathrm{K} /(\mathrm{G}-\varepsilon \alpha \tau)$ and 1. For a new appointment, the optimal policy in (6) has

$$
\mathrm{y}=0, \mathrm{r}=\mathrm{G}, \mathrm{z}=\tau \text {, and so } \mathrm{v}_{0}=(1-\varepsilon \alpha) \mathrm{V}(\mathrm{G})+\varepsilon \alpha \mathrm{V}(\mathrm{D})-\mathrm{K} \text {. }
$$

When the incumbent governor had credit $u$ at the end of the previous period, the optimal policy 
in (7) depends on $\mathrm{u}$ as follows. For $\mathrm{u}<\mathrm{G}_{\varepsilon}$ : the optimal policy is

$$
\mathrm{y}=0, \mathrm{z}=\tau, \mathrm{r}=\mathrm{G}, \mathrm{q}=1-\mathrm{u} / \mathrm{G}_{\varepsilon},
$$

and so the value function is

$$
\mathrm{V}(\mathrm{u})=\left[(1-\varepsilon \alpha) \mathrm{V}(\mathrm{G})+\varepsilon \alpha \mathrm{V}(\mathrm{D})-\left(1-\mathrm{u} / \mathrm{G}_{\varepsilon}\right) \mathrm{K}\right] /(1+\varepsilon \delta), \quad \forall \mathrm{u} \leq \mathrm{G}_{\varepsilon} .
$$

For $\mathrm{u} \geq \mathrm{G}_{\varepsilon}$, the optimal policy is

$$
\mathrm{q}=0, \mathrm{z}=\tau, \quad \mathrm{r}=\min \{\mathrm{u}+\varepsilon \delta \mathrm{u}+\varepsilon \alpha \tau, \mathrm{H}\}, \quad \varepsilon \mathrm{y}=\max \{0, \mathrm{u}+\varepsilon \delta \mathrm{u}+\varepsilon \alpha \tau-\mathrm{H}\},
$$

and so the value function is

$$
\begin{aligned}
& \mathrm{V}(\mathrm{u})=[(1-\varepsilon \alpha) \mathrm{V}(\mathrm{u}+\varepsilon \delta \mathrm{u}+\varepsilon \alpha \tau)+\varepsilon \alpha \mathrm{V}(\mathrm{u}+\varepsilon \delta \mathrm{u}+\varepsilon \alpha \tau-\tau)] /(1+\varepsilon \delta), \quad \forall \mathrm{u} \in\left[\mathrm{G}_{\varepsilon}, \mathrm{H}_{\varepsilon}\right], \\
& \mathrm{V}(\mathrm{u})=[\mathrm{u}+\varepsilon \delta \mathrm{u}+\varepsilon \alpha \tau-\mathrm{H}+(1-\varepsilon \alpha) \mathrm{V}(\mathrm{H})+\varepsilon \alpha \mathrm{V}(\mathrm{H}-\tau)] /(1+\varepsilon \delta), \quad \forall \mathrm{u} \in\left[\mathrm{H}_{\varepsilon}, \mathrm{H}\right]
\end{aligned}
$$

\section{The continuous-time limit}

Now let us consider the limit of this model as the period length $\varepsilon$ goes to 0 . In this continuous-time limit, crises occur as a Poisson process with rate $\alpha$ as long as the governor is serving correctly. But if the governor instead acted corruptly over any interval of time then crises would occur as a Poisson process with the higher rate $\beta$.

When $\varepsilon$ goes to $0, \mathrm{G}_{\varepsilon}$ goes to $\mathrm{G}$ and $\mathrm{H}_{\varepsilon}$ goes to the upper credit bound $\mathrm{H}$. Under the optimal policy from Theorem 1, when the incumbent governor's credit $\mathrm{u}$ is less than $\mathrm{G}$, the optimal policy (by (9)) is either to promote the governor to credit $\mathrm{G}$, with probability $\mathrm{u} / \mathrm{G}$, or else to dismiss the governor, with probability $\mathrm{q}=1-\mathrm{u} / \mathrm{G}$. If the incumbent is dismissed then (by (8)) a new governor is appointed who gets initial credit $\mathrm{G}$ after paying $\mathrm{K}$ for her appointment. Thus, whenever an incumbent governor's credit drops below $\mathrm{G}$, the governor must be immediately called to the prince's court for a trial to determine whether the governor is to be replaced or not, but either way, after the trial the prince will owe credit $\mathrm{G}$ to the (new or old) governor. (This equality follows from the fact that $r=G$ in both (8) and (9).) So in the continuous time, the incumbent governor's credit must almost always be between $\mathrm{G}$ and $\mathrm{H}$.

Now consider the case when the incumbent governor's credit $u$ satisfies $G \leq u<H$. Under the optimal policy from Theorem 1, during any interval of time when there are no crises, the incumbent governor continues in office without pay $(q=0, y=0)$ but her credit grows at rate

$$
\mathrm{u}^{\prime}=\delta \mathrm{u}+\alpha \tau=\lim _{\varepsilon \rightarrow 0}(\mathrm{u}+\varepsilon \delta \mathrm{u}+\varepsilon \alpha \tau-\mathrm{u}) / \varepsilon .
$$

This credit growth rate is the limit, as $\varepsilon \rightarrow 0$, of the governor's credit growth rate from $u$ to 
$\mathrm{r}=\mathrm{u}+\varepsilon \delta \mathrm{u}+\varepsilon \alpha \tau$ in any $\varepsilon$ time period of the discrete-time model in Theorem 1. But when a crisis occurs, the governor incurs the penalty $\tau=\gamma /(\beta-\alpha)$ and her credit drops from $u$ to $u-\tau$. If $u-\tau$ is less than $\mathrm{G}$, then the governor must be called to the prince's court for a trial, as specified in the preceding paragraph. Notice that $u-\tau$ is not below the rebellion threshold $D$, because $u \geq G=D+\tau$.

When the governor's credit reaches the upper bound $\mathrm{H}$, then the governor is paid at rate $\mathrm{y}=\delta \mathrm{H}+\alpha \tau$ and her credit stays constant at $\mathrm{H}$ as long as there are no crises. These results come from condition (11) in Theorem 1, which with $\mathrm{u}=\mathrm{H}$ yields $\varepsilon y=\mathrm{u}+\varepsilon \delta \mathrm{u}+\varepsilon \alpha \tau-\mathrm{H}=\varepsilon \delta \mathrm{H}+\varepsilon \alpha \tau$ and $\mathrm{r}=\mathrm{H}$. But when a crisis occurs for a governor with credit $\mathrm{H}$, her credit must drop to $\mathrm{H}-\tau$, which takes us back either to the preceding paragraph if $\mathrm{H}-\tau \geq \mathrm{G}$ or to the paragraph before that if $\mathrm{H}-\tau<\mathrm{G}$. In effect, the pay rate $\mathrm{y}$ is covering the interest on the amount $\mathrm{H}$ that is owed to the governor plus the penalty risk rate $\alpha \tau$ to which the governor is exposed by serving in office. These results may be summarized as follows.

Theorem 2. In the continuous-time model (with $\varepsilon=0$ ), the optimal policy depends on the incumbent governor's credit as follows. A newly appointed governor always starts at credit G, after paying $\mathrm{K}$ for the position. While the governor's credit $\mathrm{u}$ satisfies $\mathrm{u}<\mathrm{H}$, it grows between crises at rate $u^{\prime}=\delta u+\alpha \tau$. Any crisis causes the governor's credits to drop by the penalty amount $\tau$. If the resulting post-crisis credit $\mathrm{u}-\tau$ is less than $\mathrm{G}$, the governor is called to a trial which reinstates her at credit $\mathrm{G}$ with probability $(\mathrm{u}-\tau) / \mathrm{G}$, and otherwise the governor is dismissed and a new governor is appointed. The governor is paid only when her credit reaches the bound $\mathrm{H}$, and then she gets income at rate $\mathrm{y}=\delta \mathrm{H}+\alpha \tau$ per unit time until the next crisis causes her credit to drop to $\mathrm{H}-\tau$.

A continuous-time $(\varepsilon \rightarrow 0)$ limit of the prince's value function $V$ must exist, because these values are bounded for all $\varepsilon$. For example, a policy of keeping governors at credit $u$, with replacement probability $\tau / \mathrm{u}$ after any crisis, would be feasible for any $\varepsilon$ with pay rate $y=\delta u+\alpha \tau$, and this policy would make the prince's discounted costs equal to $u+\alpha \tau / \delta$. The prince's expected discounted cost can never be less than the amount $u$ that is owed to the current incumbent. So the value $\mathrm{V}(\mathrm{u})$ in any $\varepsilon$-discrete-time model must be between $u$ and $u+\alpha \tau / \delta$.

For any positive $\varepsilon$, the value equations (10), (12), and (13) in Theorem 1 imply

$$
\mathrm{V}^{\prime}(\mathrm{u})=\mathrm{K} /(\mathrm{G}-\varepsilon \alpha \tau) \text { when } \mathrm{u}<\mathrm{G}_{\varepsilon},
$$




$$
\begin{aligned}
& \mathrm{V}(\mathrm{u}+\varepsilon \delta \mathrm{u}+\varepsilon \alpha \tau)-\mathrm{V}(\mathrm{u})=\varepsilon \delta \mathrm{V}(\mathrm{u})+\varepsilon \alpha[\mathrm{V}(\mathrm{u}+\varepsilon \delta \mathrm{u}+\varepsilon \alpha \tau)-\mathrm{V}(\mathrm{u}+\varepsilon \delta \mathrm{u}+\varepsilon \alpha \tau-\tau)] \\
& \text { when } \mathrm{G}_{\varepsilon} \leq \mathrm{u} \leq \mathrm{H}_{\varepsilon}
\end{aligned}
$$$$
\text { and } \mathrm{V}^{\prime}(\mathrm{u})=1 \text { when } \mathrm{u}>\mathrm{H}_{\varepsilon} \text {. }
$$

Taking limits as $\varepsilon \rightarrow 0$, the continuous-time value function must satisfy

$$
\begin{aligned}
& \mathrm{V}^{\prime}(\mathrm{u})=\mathrm{K} / \mathrm{G}, \forall \mathrm{u}<\mathrm{G} ; \\
& \mathrm{V}^{\prime}(\mathrm{u})=[(\delta+\alpha) \mathrm{V}(\mathrm{u})-\alpha \mathrm{V}(\mathrm{u}-\tau)] /(\delta \mathrm{u}+\alpha \tau), \forall \mathrm{u} \in[\mathrm{G}, \mathrm{H}] ; \\
& \mathrm{V}^{\prime}(\mathrm{H})=1 .
\end{aligned}
$$

The continuous-time value function $\mathrm{V}$ is continuous and convex on its domain $[\mathrm{D}, \mathrm{H}]$. but it has a kink at $\mathrm{u}=\mathrm{G}$, where the right derivative $\mathrm{V}^{\prime}(\mathrm{G})=[(\delta+\alpha) \mathrm{V}(\mathrm{G})-\alpha \mathrm{V}(\mathrm{D})] /(\delta \mathrm{G}+\alpha \tau)$ may be strictly greater than the left derivative $K / G$. But the derivative $V^{\prime}(u)$ is continuous at $u=H$, because equation (13) at $\mathrm{u}=\mathrm{H}$ implies that all discrete-time models satisfy the equation

$$
(\delta+\alpha) \mathrm{V}(\mathrm{H})-\alpha \mathrm{V}(\mathrm{H}-\tau)=\delta \mathrm{H}+\alpha \tau \text {. }
$$

We may also define the value function $\mathrm{V}(0)$ to be the prince's expected discounted value of net costs when the position of governor is unfilled. Since the optimal policy then is to immediately hire a new governor who gets credit $\mathrm{G}$ after paying $\mathrm{K}$ for her office, we have

$$
\mathrm{V}(0)=\mathrm{V}(\mathrm{G})-\mathrm{K} \text {. }
$$

That is, the linear slope $\mathrm{V}^{\prime}(\mathrm{u})=\mathrm{K} / \mathrm{G}$ can be applied over the whole interval from 0 to $\mathrm{G}$, and so the convex function $\mathrm{V}(\mathrm{u})$ can be extended to any $\mathrm{u}$ in the interval $[0, \mathrm{H}]$.

We now show how the continuous-time value function $\mathrm{V}$ can be computed numerically. The trick is to consider the function $\Psi$ such that

$$
\Psi(\mathrm{u})=(\mathrm{V}(\mathrm{u})-\mathrm{uK} / \mathrm{G}) / \mathrm{V}(0), \forall \mathrm{u} \in[0, \mathrm{H}] .
$$

With equations (14)-(17), this function $\Psi$ satisfies the equations

$$
\begin{aligned}
& \text { if } \mathrm{u} \leq \mathrm{G} \text { then } \Psi(\mathrm{u})=1 \\
& \text { if } \mathrm{u} \geq \mathrm{G} \text { then } \Psi^{\prime}(\mathrm{u})=[(\delta+\alpha) \Psi(\mathrm{u})-\alpha \Psi(\mathrm{u}-\tau)] /(\delta \mathrm{u}+\alpha \tau) .
\end{aligned}
$$

(To verify (19), notice that the differential equation in (15) is linear in V, and it would also be satisfied by the linear function $\mathrm{uK} / \mathrm{G}$.) The following result, which is proven in section 10 , shows that this function $\Psi$ gives us a practical method for computing the continuous-time value function $\mathrm{V}$.

Theorem 3. An increasing convex function $\Psi$ can be uniquely characterized by equations (18) and (19). This function $\Psi(\mathrm{u})$ is continuous, but its derivative $\Psi^{\prime}(\mathrm{u})$ has one discontinuity at 
$\mathrm{u}=\mathrm{G}$, where equation (19) yields the right derivative $\Psi^{\prime}(\mathrm{G})=\delta /(\delta \mathrm{G}+\alpha \tau)$ that applies for small increases $\mathrm{u} \geq \mathrm{G}$. When $\mathrm{u} \geq \mathrm{G}$, the derivative $\Psi^{\prime}(\mathrm{u})$ is strictly increasing in $\mathrm{u}$. Then in the continuous-time limit $(\varepsilon=0)$, the optimal value function $V$ that satisfies equations (14)-(16) can be computed from $\Psi$ by the formula

$$
\mathrm{V}(\mathrm{u})=\mathrm{uK} / \mathrm{G}+\Psi(\mathrm{u})(1-\mathrm{K} / \mathrm{G}) / \Psi^{\prime}(\mathrm{H}), \quad \forall \mathrm{u} \in[0, \mathrm{H}]
$$

The fact that $\Psi^{\prime}(\mathrm{u})$ is strictly increasing in $\mathrm{u}$ when $\mathrm{u} \geq \mathrm{G}$ also imply the following important comparative-statics result for $\mathrm{V}(0)=(1-\mathrm{K} / \mathrm{G}) / \Psi^{\prime}(\mathrm{H})$.

Theorem 4. When all other parameters are held fixed, an increase of the trust bound $\mathrm{H}$ would strictly decrease $\mathrm{V}(0)$, the expected present-discounted value of the prince's cost when a new governor is first appointed.

To illustrate this solution, let us consider a numerical example where the discount rate is $\delta=0.05$, the normal crisis rate is $\alpha=0.1$, the corrupt crisis rate is $\beta=0.3$, the corrupt income rate is $\gamma=1$, the expected value of rebellion is $\mathrm{D}=5$, candidates have payable assets worth $\mathrm{K}=1$, and the upper bound on the prince's debt to any governor is $\mathrm{H}=25$. With these parameters, the crisis penalty is $\tau=\gamma /(\beta-\alpha)=5$, and the minimal credit for governors is $\mathrm{G}=\mathrm{D}+\tau=10$.

Figure 1 shows the how the prince's expected cost $\mathrm{V}(\mathrm{u})$ depends on the debt $\mathrm{u}$ that is owed to the current governor. The prince's expected cost when appointing a new governor would be $V(0)=V(G)-K=10.44$ for this example. The slope of the cost function $V^{\prime}$ is 0.1 from $u=0$ to $\mathrm{u}=\mathrm{G}=10$, but there is a kink at $\mathrm{u}=10$ where the slope jumps to 0.622 , and then the slope increases continuously to 1 at $\mathrm{H}=25$.

\section{[Insert Figures 1 and 2 about here]}

Figure 2 shows how the prince's expected cost $\mathrm{V}(\mathrm{G})-\mathrm{K}$ would change if the upper bound $\mathrm{H}$ were changed, holding fixed all other parameters of this example. The curve in Figure 2 is computed by applying the formula $\mathrm{V}(\mathrm{G})-\mathrm{K}=(1-\mathrm{K} / \mathrm{G}) / \Psi^{\prime}(\mathrm{H})$, where $\Psi(\mathrm{u})$ can be extended to all $\mathrm{u} \geq \mathrm{G}$ by the differential equation (19). The curve cannot be extended to $\mathrm{H}<\mathrm{G}$, because the incentive constraints (2)-(4) would become impossible to satisfy if the credit bound $\mathrm{H}$ were less than the minimal credit level $\mathrm{G}=\mathrm{D}+\gamma /(\beta-\alpha)$. Increasing the credit bound $\mathrm{H}$ would decrease the prince's expected cost $\mathrm{V}(\mathrm{G})-\mathrm{K}$ when a new governor is appointed, here from an expected cost of 
18 when the credit bound is 10 , to an expected cost of 10.42 when the credit bound approaches infinity. This negative slope in Figure 2 is implied by Theorem 4 above.

\section{Properties of the long-run stationary distribution}

When a new state is established, its prince can promise the minimal credit $\mathrm{G}$ to newly appointed governors in all provinces. But as the optimal incentive policy is applied over time, the credit owed to the governor of each province will move randomly over the interval $[\mathrm{G}, \mathrm{H}]$ according to an independent stochastic process. Assuming that there are many provinces, the distribution of governors' credits across all provinces should be expected to converge in the long run to a stationary distribution. Thus, the stationary distribution of governors' credits indicates the magnitude of agency debts that may be rationally incurred by the prince in a mature state.

So now let us consider the long-run stationary distribution of the governor's credit $u$ under the optimal incentive plan in the continuous-time model. Let $\mathrm{F}$ denote the strict cumulative distribution of $\mathrm{u}$ in this stationary distribution; that is, $\mathrm{F}(\mathrm{u})$ denotes the probability that the governor's credit is strictly less than $u$. The governor almost always has a credit in the interval $[\mathrm{G}, \mathrm{H}]$. (The governor's expected credit may be between D and G during post-crisis trials, but they are assumed to be infinitesimally brief.) So this strict cumulative F satisfies

$$
\begin{aligned}
& \mathrm{F}(\mathrm{u})=0 \text { if } \mathrm{u} \leq \mathrm{G}, \\
& \mathrm{F}(\mathrm{u})=1 \text { if } \mathrm{u}>\mathrm{H} .
\end{aligned}
$$

We can have $\mathrm{F}(\mathrm{H})<1$, and $1-\mathrm{F}(\mathrm{H})$ denotes the probability that the governor's credit is $\mathrm{H}$.

Now consider any $u$ between $G$ and $H . F(u+\tau)-F(u)$ is the probability of a governor being at $\mathrm{u}$ or above by less than the penalty amount $\tau$, and the probability of incurring a penalty $\tau$ during a short interval of length $\varepsilon$ is approximately $\varepsilon \alpha$. So to a first-order approximation in $\varepsilon$, the probability of the governor's credit dropping across $u$ in a crisis during a short interval of length $\varepsilon$ is $\varepsilon \alpha[F(u+\tau)-F(u)] . F^{\prime}(u)$ is the probability density at $u$, and near $u$ the governor's credit increases between crises at the rate $\mathrm{u}^{\prime}=\delta \mathrm{u}+\alpha \tau$. So the probability of a governor being below $\mathrm{u}$ by a small amount $\varepsilon(\delta \mathrm{u}+\alpha \tau)$ such that the governor's credit would increase across u during a short interval of length $\varepsilon$, is $\varepsilon(\delta \mathrm{u}+\alpha \tau) \mathrm{F}^{\prime}(\mathrm{u})$, to a first-order approximation in $\varepsilon$. In the stationary distribution, the probability of crossing $\mathrm{u}$ in each direction must be the same. Thus, $\mathrm{F}$ must satisfy the differential equation

$$
(\delta \mathrm{u}+\alpha \tau) \mathrm{F}^{\prime}(\mathrm{u})=\alpha[\mathrm{F}(\mathrm{u}+\tau)-\mathrm{F}(\mathrm{u})], \quad \forall \mathrm{u} \in[\mathrm{G}, \mathrm{H}] .
$$


To compute F, we may consider the function $\Omega$ defined by

$$
\begin{aligned}
& \Omega(\mathrm{u})=0 \quad \forall \mathrm{u}>\mathrm{H}, \Omega(\mathrm{H})=1, \\
& -\Omega^{\prime}(\mathrm{u})=\alpha[\Omega(\mathrm{u})-\Omega(\mathrm{u}+\tau)] /(\delta \mathrm{u}+\alpha \tau) \quad \forall \mathrm{u} \leq \mathrm{H} .
\end{aligned}
$$

This function $\Omega$ satisfies the same differential equation as $\mathrm{F}$ but with different boundary conditions. The differential equation can used to numerically compute $\Omega(\mathrm{u})$ continuously for all $\mathrm{u} \leq \mathrm{H}$. But $[1-\mathrm{F}(\mathrm{u})] /[1-\mathrm{F}(\mathrm{H})]$ satisfies the same conditions as $\Omega(\mathrm{u})$ when $\mathrm{u} \geq \mathrm{G}$, and so

$$
\Omega(\mathrm{u})=[1-\mathrm{F}(\mathrm{u})] /[1-\mathrm{F}(\mathrm{H})], \forall \mathrm{u} \geq \mathrm{G} .
$$

Then with $F(G)=0$, we get $\Omega(G)=1 /[1-F(H)]$, and so $F$ can be computed from $\Omega$ by

$$
\mathrm{F}(\mathrm{u})=1-\Omega(\mathrm{u}) / \Omega(\mathrm{G}), \forall \mathrm{u} \geq \mathrm{G} .
$$

The stationary distribution $\mathrm{F}$ has a continuous probability density

$$
\mathrm{F}^{\prime}(\mathrm{u})=-\Omega^{\prime}(\mathrm{u}) / \Omega(\mathrm{G})
$$

on the interval $[\mathrm{G}, \mathrm{H})$, but there is also has a discrete probability mass $1-\mathrm{F}(\mathrm{H})$ at the upper bound $\mathrm{H}$, where the governor gets paid.

Figure 3 shows the cumulative distribution $F$ for our example from section 4 , with $\alpha=0.1$, $\beta=0.3, \delta=0.05, \mathrm{D}=5, \mathrm{~K}=1$, and $\mathrm{H}=25$. In the stationary distribution, the probability of a governor being at the credit bound $\mathrm{H}$ is $1-\mathrm{F}(\mathrm{H})=0.68$.

\section{[Insert Figure 3 about here]}

The pay rate for governors at $\mathrm{H}$ is $\delta \mathrm{H}+\alpha \tau=0.05 \times 25+0.1 \times 5=1.75$ here. So in the stationary distribution, the prince's expected wage-expense rate is

$$
(\delta \mathrm{H}+\alpha \tau)(1-\mathrm{F}(\mathrm{H}))=1.19 .
$$

A crisis can cause a governor to be dismissed only when the governor's pre-crisis credit was between $\mathrm{G}$ and $\mathrm{G}+\tau$, which is between 10 and 15 for this example, but the stationary probability of this interval is $\mathrm{F}(15)=0.015$. The expected rate of dismissals in the stationary distribution is

$$
\left.\int_{\mathrm{u} \in[\mathrm{G}, \mathrm{G}+\tau]} \alpha[1-(\mathrm{u}-\tau) / \mathrm{G})\right] \mathrm{dF}(\mathrm{u})=0.00030,
$$

So in the stationary distribution, the prince's expected discounted value of net wage costs (wage expenses, minus payments from new governors) is

$$
(1.19-0.00030 \mathrm{~K}) / \delta=23.8 \text {. }
$$

This stationary discounted cost is much greater than the prince's expected discounted cost when he appoints a new governor, which is $\mathrm{V}(\mathrm{G})-\mathrm{K}=10.44$ for this example. When a new governor is appointed, the prince can reduce the expected discounted value of his costs by 
planning to defer compensation until his debts reach the credit bound $\mathrm{H}$. But then the prince's costs will become greater after the debt of $\mathrm{H}$ has been incurred, and the stationary distribution takes this ex-post perspective.

For comparison, if the credit bound $\mathrm{H}$ were at the smallest feasible level $\mathrm{H}=\mathrm{G}=10$, holding fixed the other parameters of this example, then the prince would always pay his governor $\mathrm{y}=\delta \mathrm{G}+\alpha \tau=1$, and governors would be dismissed at the expected rate $\alpha[1-(\mathrm{G}-\tau) / \mathrm{G}]=$ 0.05 . So the prince's expected costs when would normally be worth $\mathrm{V}(\mathrm{G})=(\mathrm{y}-0.05 \mathrm{~K}) / \delta=19$, which would decline to $\mathrm{V}(\mathrm{G})-\mathrm{K}=18$ when a new governor is appointed. Thus, a lower credit bound $\mathrm{H}$ would make the prince worse off ex ante, when a new governor is first appointed, but it could make the prince better off ex post, in the long-run stationary distribution.

In this example, the prince's ex-post stationary expected cost rate actually declines as the credit bound $\mathrm{H}$ increases from 10 to 15 , but it becomes increasing in $\mathrm{H}$ when $\mathrm{H}>15$. This result for large $\mathrm{H}$ can be shown to hold in broad generality. The following theorem tells us that, if $\mathrm{H}$ is large, then a governor's credit is unlikely to be far from $\mathrm{H}$ in the stationary distribution. The proof can be found in section 10 .

Theorem 5. The stationary strict cumulative distribution $\mathrm{F}$ satisfies, for any integer $\mathrm{m} \geq 0$,

$$
\text { if } \mathrm{u} \leq \mathrm{H}-\mathrm{m} \tau \text { then } \mathrm{F}(\mathrm{u}) \leq[\alpha \tau /(\delta \mathrm{G}+\alpha \tau)]^{\mathrm{m}+1} \text {. }
$$

When credit $\mathbf{u}$ is drawn from the stationary distribution F, its expected value satisfies

$$
\mathrm{E}(\mathbf{u}) \geq \mathrm{H}-\alpha \tau^{2} /(\delta \mathrm{G}),
$$

and its probability of being at the upper bound $\mathrm{H}$ satisfies

$$
\mathrm{P}(\mathbf{u}=\mathrm{H})=1-\mathrm{F}(\mathrm{H}) \geq\left(\delta \mathrm{H}-\alpha \tau^{2} / \mathrm{G}\right) /(\delta \mathrm{H}+\alpha \tau) .
$$

The bounds in Theorem 5 imply that the long-run stationary probability of being at the upper credit bound $\mathrm{H}$ goes to 1 as $\mathrm{H}$ becomes large, that is, $1-\mathrm{F}(\mathrm{H}) \rightarrow 1$ as $\mathrm{H} \rightarrow \infty$. So when $\mathrm{H}$ is large, the leader is in the long run usually paying high wages $\delta \mathrm{H}+\alpha \tau$ to each governor. The longrun expected pay rate $(\delta \mathrm{H}+\alpha \tau)(1-\mathrm{F}(\mathrm{H}))$ is bounded below by $\delta \mathrm{H}-\alpha \tau^{2} / \mathrm{G}$, which goes to infinity as $\mathrm{H}$ becomes large.

We have seen (as in Figure 2) that the prince's expected discounted costs when a new governor is appointed are strictly decreasing in the upper bound $\mathrm{H}$. Thus, even when the leader is secure in power and is as patient as his agents (discounting the future at the same rate $\delta$ ), 
agency costs can give the leader an incentive to accumulate large expensive debts to governors.

The governors' turnover rate is bounded above by the inequality

$$
\left.\int_{\mathrm{u} \in[\mathrm{G}, \mathrm{G}+\tau]} \alpha[1-(\mathrm{u}-\tau) / \mathrm{G})\right] \mathrm{dF}(\mathrm{u}) \leq \alpha \mathrm{F}(\mathrm{G}+\tau) .
$$

The bounds in Theorem 5 imply that $\mathrm{F}(\mathrm{G}+\tau)$ goes to 0 as $\mathrm{H}$ becomes large. So when the prince has a high credit bound $\mathrm{H}$, successful governors tend to become entrenched in office as a closed aristocracy. The prince prefers such a system that minimizes new entry into high office, because he expects to lose $\mathrm{G}-\mathrm{K}$ whenever he promotes an outside candidate who can only pay $\mathrm{K}$ for an position that is worth $\mathrm{G}$.

\section{Analysis of the solution}

Whenever a new governor is appointed, the prince incurs a liability worth $G$ in exchange for a smaller payment $\mathrm{K}$, and so the prince's expected net cost from any promotion must be $\mathrm{G}-\mathrm{K}$. The prince's total expected discounted cost is equal to the expected present discounted value of his net costs from all future appointments. Thus, the optimal incentive plan for the prince should minimize the expected frequency of replacing governors.

In a model that is similar to ours, Akerlof and Katz found no advantage to delayed wage increases, but they assumed that crises do not occur when an official serves correctly. That is, in our terms, their model assumed that $\alpha$ would equal zero. But in our model, with $\alpha>0$, deferring a governor's compensation until the credit bound $\mathrm{H}$ is reached can help to reduce the prince's expected discounted cost by reducing the expected turnover of governors, because some crises can be punished by temporary suspension of wages instead of by dismissal.

Ex post, however, the (unanticipated) replacement of a governor who has been promised $\mathrm{u} \geq \mathrm{G}$ would yield benefits to the prince worth $\mathrm{K}+\mathrm{V}(\mathrm{u})-\mathrm{V}(\mathrm{G})>0$. Thus, although the prince wants ex ante to promise a low rate of turnover among his governors, they must always be suspicious that ex post he may try to find excuses to violate this promise and deny their promised rewards. In our model, the parameter $\mathrm{H}$ represents the bound on how much the prince can credibly promise any governor.

We have seen that, to deter his governors from corruption and rebellion, the prince's credit bound $\mathrm{H}$ cannot be less than the minimal credit level $\mathrm{G}$ that a loyal governor requires. If governors could not trust the prince to pay them future rewards worth $\mathrm{D}$, then they would rebel immediately. If the prince's credit bound were between $\mathrm{D}$ and $\mathrm{G}$, then he could deter governors 
from rebellion, but he could not penalize crises sufficiently to deter governors from corruption.

In the optimal incentive plan, by (9), the prince randomizes between dismissal and reinstatement of the current governor after crises when the governor's prior credit was below $\mathrm{G}+\tau$. The threat of dismissal must be moderated by randomization here, because otherwise it would incite governors to rebel after crises. Within our model, any procedure in the prince's court that implements this randomization could be considered a "fair trial" for the governor. But in such a trial, the prince would actually prefer to dismiss rather than reinstate because, after a dismissal, he can get a new candidate to pay $\mathrm{K}>0$ for promotion into the office of governor. Thus, the positive probability of reinstatement in such trials can be credible only if it is guaranteed by some institutional constraint on the prince.

The fairness of these trials must be actively monitored, because the correct outcome of the trial cannot depend only on the facts of the case but must also depend on some unpredictable element in the trial itself. If the correct outcome of a governor's trial depended predictably on the nature of the crisis in her province, then the governor would rebel before any trial that was to result in her dismissal, because the governor observes the crisis before she is called to court. Thus, the outcome of the trial must depend on unpredictable random events in the trial, and the correctness of the outcome can be verified only by people who have observed the process of the trial in detail.

Who can punish a sovereign prince for wrongly dismissing a governor in an unfair trial? We have not formally modeled the prince's payoffs here, but we have assumed that corruption and rebellion would be very costly for the prince, perhaps because they could terminate his reign. So governors and other high officials, as a group, have the power to punish such misbehavior by the prince. If the prince were known to have wrongly dismissed a governor in an unfair trial, then other governors could lose trust in future trials, so that they would rebel after any crisis. That is, the prince could be deterred from cheating a governor by the threat that his perceived credit bound would drop below $\mathrm{G}$ if such cheating were observed. Thus, within our model, the prince can guarantee the fairness of a governor's trials by inviting other governors to observe it. The effectiveness of the threat here depends on a sense of identity among the high officials who serve the prince, so that they would all lose faith in the prince's promises if he cheats any one of them. (See Myerson, 2008, for further discussion of this crucial point. Enforcement by loss of reputations with future agents has also been modeled by Bull, 1987.) 
Other alternatives to randomized trials would be more costly to the prince in our model. Our analysis allowed for the possibility that governors could be punished or given severance pay, but neither is used in the optimal solution. For example, consider the situation when a governor's expected credit drops to $\mathrm{u}-\tau<\mathrm{G}$ after a crisis. Dismissing the governor with severance pay $\mathrm{u}-\tau$ would make the prince's expected cost $\mathrm{V}(\mathrm{G})+\mathrm{u}-\tau-\mathrm{K}$, as a new governor would pay $\mathrm{K}$ for appointment to credit $\mathrm{G}$. On the other hand, reinstating the old governor at the minimal credit $\mathrm{G}$ after inflicting a corporal punishment that hurts her as much as an income loss of $\mathrm{G}-(\mathrm{u}-\tau)$ would make the prince's expected cost $\mathrm{V}(\mathrm{G})$, given that such corporal punishments have no benefit to the prince. With $0<\mathrm{K}<\mathrm{G}$, both of these expected costs are strictly greater than the prince's expected cost $\mathrm{V}(\mathrm{u}-\tau)=\mathrm{V}(\mathrm{G})+(\mathrm{u}-\tau) \mathrm{K} / \mathrm{G}-\mathrm{K}$ under the optimal plan with randomized dismissal. Severance pay is not optimal because it increases the expected rate of turnover, which is costly for the prince when $\mathrm{K}<\mathrm{G}$. Corporal punishment could decrease the expected rate of turnover but is not optimal because, when $\mathrm{K}>0$, the prince would have to pay more to compensate governors for their anticipated risk of corporal punishment than the prince could gain by reducing turnover.

\section{Tolerating low effort with a soft budget constraint}

Now let us relax the assumption that the prince will never tolerate corruption. To endogenize the decision about whether deterrence of corruption is worthwhile, we need to take the cost of corruption into account. To keep things simple, let us assume that the prince's loss from corruption is entirely due to the increased rate of crises that it causes, where each crisis costs the prince some amount L. We continue to assume here that the prince's (unspecified) cost of rebellions is large enough that he wants to always deter rebellion, so the prince's trust bound cannot be less than the governor's rebellion payoff, that is, $\mathrm{H} \geq \mathrm{D}$. Also for simplicity, let us assume now that candidates for governor cannot pay anything for promotion to governor, that is, $\mathrm{K}=0$.

What we have been calling corruption may be reinterpreted as low effort against crises, and good service is high effort. It will be convenient for us now to reinterpret $\gamma$ as the governor's unmonitorable cost for high effort that can reduce the expected rate of crises (instead of as the governor's hidden income from corruption that would increase the rate of crises). So we assume now that the prince must pay an additional rate $\gamma$ to the governor to cover these costs whenever 
high effort is demanded. To make sure that high effort would be economically efficient if it were observable, let us make the parametric assumption

$$
\beta \mathrm{L}>\alpha \mathrm{L}+\gamma, \text { that is, } \mathrm{L}>\gamma /(\beta-\alpha)=\tau .
$$

This $\gamma$ expenditure allowance is not counted as income to the governor because she is supposed to be spending it on the high effort against crises, but there is a moral-hazard problem because the prince cannot directly observe the governor's effort expenditures. So although the prince may demand high effort and pay the allowance necessary for it, the governor can always choose low effort and spend the $\gamma$ allowance on her own consumption instead. The governor would prefer this low-effort alternative if her expected penalty for new crises were less than $\tau=\gamma /(\beta-\alpha)$.

Let W(u) denote the optimal expected present-discounted value of prince's future costs when the governor has been promised credit $u$, including now the cost of crises and the effort cost $\gamma$ which the prince must pay when the governor is supposed to choose high effort. So this value $\mathrm{W}(\mathrm{u})$ differs from the value $\mathrm{V}(\mathrm{u})$ that we analyzed above in that $\mathrm{W}(\mathrm{u})$ also includes the expected discounted cost of crises and high effort, which would be $(\alpha \mathrm{L}+\gamma) / \delta$ in the case where the governor always maintains high effort.

Recall from section 3 the discrete-time model with time periods of length $\varepsilon$. To accommodate our new assumptions, this model must be revised by permitting that, at the first stage of each period, the prince also has the option to advise the governor to exert low effort, in which case the prince would not pay the $\varepsilon \gamma$ effort-cost allowance. So in each period the prince would now have two additional decision variables, the probability $\mathrm{p}$ of the governor being advised to exert low effort, and the expected future credit $\mathrm{s}$ for the governor at the end of the period if low effort was advised. Then the promise-keeping constraint (1) becomes

$$
\varepsilon y+p s+(1-q-p)[(1-\varepsilon \alpha) r+\varepsilon \alpha(r-z)] \geq(1+\varepsilon \delta) u .
$$

The noncorruption constraint (2) or ( $\left.2^{\prime}\right)$ remains the same (for the event that high effort is advised, which now has probability $1-\mathrm{q}-\mathrm{p}$ ), and the other constraints are changed only by appropriate upper and lower bounds for s and q:

$$
\begin{aligned}
& \mathrm{z} \geq \tau, \\
& \mathrm{r}-\mathrm{z} \geq \mathrm{D}, \quad \mathrm{s} \geq \mathrm{D}, \\
& \mathrm{r} \leq \mathrm{H}, \quad \mathrm{s} \leq \mathrm{H}, \\
& \mathrm{y} \geq 0, \quad \mathrm{p} \geq 0, \quad \mathrm{q} \geq 0, \quad \mathrm{p}+\mathrm{q} \leq 1 .
\end{aligned}
$$

When a new governor is appointed, the prince's optimal expected value becomes 


$$
\begin{aligned}
& \mathrm{w}_{0}=\operatorname{minimum}_{\mathrm{y}, \mathrm{p}, \mathrm{s}, \mathrm{r}, \mathrm{z}} \varepsilon \mathrm{y}+\mathrm{p}[\mathrm{W}(\mathrm{s})+\varepsilon \beta \mathrm{L}]+(1-\mathrm{p})[(1-\varepsilon \alpha) \mathrm{W}(\mathrm{r})+\varepsilon \alpha \mathrm{W}(\mathrm{r}-\mathrm{z})+\varepsilon \alpha \mathrm{L}+\varepsilon \gamma] \\
& \text { subject to }\left(2^{\prime}\right)-\left(5^{\prime}\right) .
\end{aligned}
$$

Then for any credit $u$ that the incumbent governor could expect at the end of the end of any period, the prince's expected future value $\mathrm{W}(\mathrm{u})$ must satisfy the recursion equation:

$$
\begin{aligned}
\mathrm{W}(\mathrm{u})=\operatorname{minimum}_{\mathrm{y}, \mathrm{q}, \mathrm{p}, \mathrm{s}, \mathrm{r}, \mathrm{z}}\left\{\varepsilon \mathrm{y}+\mathrm{qw}_{0}+\mathrm{p}[\mathrm{W}(\mathrm{s})+\varepsilon \beta \mathrm{L}]+\right. \\
+(1-\mathrm{q}-\mathrm{p})[(1-\varepsilon \alpha) \mathrm{W}(\mathrm{r})+\varepsilon \alpha \mathrm{W}(\mathrm{r}-\mathrm{z})+\varepsilon \alpha \mathrm{L}+\varepsilon \gamma]\} /(1+\varepsilon \delta) \\
\quad \text { subject to }\left(1^{\prime}\right)-\left(5^{\prime}\right) .
\end{aligned}
$$

The optimal solution to this problem will depend on whether the value function $V$ from Theorem 1 satisfies the following inequality

$$
\mathrm{V}(\mathrm{D}) \leq(\beta \mathrm{L}-\alpha \mathrm{L}-\gamma) / \delta .
$$

For reasons that will be discussed below, the case when this inequality is satisfied may be called the hard budget constraint or $H B C$ case. The case when $\mathrm{V}(\mathrm{D})>(\beta \mathrm{L}-\alpha \mathrm{L}-\gamma) / \delta$ may be called the soft budget constraint or $S B C$ case. As $\beta>\alpha$ and $V(D)$ does not depend on the parameter $\mathrm{L}$, the $\mathrm{HBC}$ case applies whenever $\mathrm{L}$ is large enough. Notice that, with $\mathrm{K}=0$ here, we have

$$
\mathrm{V}(\mathrm{D})=\mathrm{V}(0)=\mathrm{V}\left(\mathrm{G}_{\varepsilon}\right)=\mathrm{v}_{0} /(1+\varepsilon \delta)=[(1-\varepsilon \alpha) \mathrm{V}(\mathrm{G})+\varepsilon \alpha \mathrm{V}(\mathrm{D})] /(1+\varepsilon \delta)
$$

which converges to $\mathrm{V}(\mathrm{G})$ as $\varepsilon \rightarrow 0$.

The prince's optimal policy is characterized in the following theorem. In the HBC case, the optimal policy is the same as before, and a governor has a positive probability of being dismissed whenever her credit drops below $\mathrm{G}_{\varepsilon}$ after a crisis. But in the SBC case, the optimal policy always has $\mathrm{q}=0$, which means that a governor is never dismissed under this policy. So the policy in this SBC case corresponds to a soft budget constraint because, no matter how many crises the governor may cause, the prince will bear the cost of them all without dismissing the governor. A new governor starts at the low credit $\mathrm{D}$, just enough to deter rebellion, and must wait a long time (duration approximately $\mathrm{LN}(\mathrm{G} / \mathrm{D}) / \delta$ ) before the prince will invite her to begin exerting high effort. Then, when high effort is recommended, the governor will begin getting the $\gamma$ effort-cost allowance, and her credit will begin rising from $\mathrm{G}$ at rate $\delta \mathrm{u}+\alpha \tau$, but she will be exposed to $\tau$ penalty losses when crises occur, just as in the HBC case. In both the SBC and HBC cases, the governor is paid an income y above the effort-cost allowance only when her credit gets close to the trust bound $\mathrm{H}$. The theorem is proven in section 10 .

Theorem 6. Let $\mathrm{V}$ be the prince's value function from the discrete-time model in 
Theorem 1 (where low effort could not be tolerated) with short period length $\varepsilon$ and with $\mathrm{K}=0$. Now consider the incentive problem when low effort can be tolerated. If $\mathrm{V}(\mathrm{D}) \leq(\beta \mathrm{L}-\alpha \mathrm{L}-\gamma) / \delta$ (the HBC case) then the prince's optimal policies in $\left(6^{\prime}\right)$ and $\left(7^{\prime}\right)$ have $p=0$ always, so that low effort is never recommended, and have (y,r,z,q) always the same as in Theorem 1, and the optimal values are

$$
\mathrm{W}(\mathrm{u})=\mathrm{V}(\mathrm{u})+(\alpha \mathrm{L}+\gamma) / \delta, \quad \forall \mathrm{u} \in[\mathrm{D}, \mathrm{H}] .
$$

If $\mathrm{V}(\mathrm{D})>(\beta \mathrm{L}-\alpha \mathrm{L}-\gamma) / \delta$ (the $\mathrm{SBC}$ case), then for a new governor the optimal policy in $\left(6^{\prime}\right)$ has

$$
\mathrm{y}=0, \mathrm{p}=1, \mathrm{~s}=\mathrm{D}, \mathrm{r}=\mathrm{G}, \mathrm{z}=\tau \text {, and so } \mathrm{w}_{0}=\varepsilon \beta \mathrm{L}+\mathrm{W}(\mathrm{D}) ;
$$

and, for any value $u$ of an incumbent governor's credit, optimal policies in $\left(7^{\prime}\right)$ have

$$
\mathrm{z}=\tau, \mathrm{r}=\max \{\mathrm{G}, \min \{\mathrm{u}+\varepsilon \delta \mathrm{u}+\varepsilon \alpha \tau, \mathrm{H}\}\}, \quad \varepsilon \mathrm{y}=\max \{0, \mathrm{u}+\varepsilon \delta \mathrm{u}+\varepsilon \alpha \tau-\mathrm{H}\},
$$

(which are the same as in Theorem 1) and have

$$
\begin{aligned}
& \text { if } \mathrm{u}<\mathrm{G}_{\varepsilon} \text { then } \mathrm{q}=0, \mathrm{~s}=\min \left\{\mathrm{u}+\varepsilon \delta \mathrm{u}, \mathrm{G}_{\varepsilon}\right\} \text {, and } \mathrm{p}=\left(\mathrm{G}_{\varepsilon}-\mathrm{u}\right) /\left[\mathrm{G}_{\varepsilon}-\mathrm{s} /(1+\varepsilon \delta)\right], \\
& \text { if } \mathrm{u} \geq \mathrm{G}_{\varepsilon} \text { then } \mathrm{q}=0, \mathrm{p}=0 \text {, and } \mathrm{s} \text { is irrelevant; }
\end{aligned}
$$

and the optimal values are

$$
\mathrm{W}(\mathrm{u})=\mathrm{u}+(\mathrm{V}(\mathrm{u})-\mathrm{u})(\beta \mathrm{L}-\alpha \mathrm{L}-\gamma) /(\delta \mathrm{V}(\mathrm{D}))+(\alpha \mathrm{L}+\gamma) / \delta, \quad \forall \mathrm{u} \geq \mathrm{D} .
$$

Taking the limit as $\varepsilon \rightarrow 0$, these optimal solutions can be extended to a continuous-time model where low effort can be tolerated, where the V function is as in Theorem 3. In this continuous-time limit, the governor's credit grows between crises at rate $u^{\prime}=\delta u$ when $u<G$ and at rate $\mathrm{u}^{\prime}=\delta \mathrm{u}+\alpha \tau$ when $\mathrm{G} \leq \mathrm{u}<\mathrm{H}$.

In the parametric case where $\mathrm{H}=\mathrm{G}$, we would get $\mathrm{V}(\mathrm{D})=\mathrm{V}(\mathrm{G})=(\delta \mathrm{G}+\alpha \tau) / \delta$, because motivating high effort while maintaining credit $\mathrm{G}$ would require a constant wage $\delta \mathrm{G}+\alpha \tau$. The HBC case applies at this $\mathrm{H}=\mathrm{G}$ case when $(\delta \mathrm{G}+\alpha \tau) / \delta \leq(\beta \mathrm{L}-\alpha \mathrm{L}-\gamma) / \delta$, which is equivalent to

$$
\mathrm{L} \geq(\delta \mathrm{G}+\alpha \tau+\gamma) /(\beta-\alpha) .
$$

With higher $\mathrm{H}, \mathrm{V}(\mathrm{D})$ becomes smaller, and so parametrically increasing $\mathrm{H}$ can never cause a switch from the $\mathrm{HBC}$ case to the SBC case. Thus, if $\mathrm{L} \geq(\delta \mathrm{G}+\alpha \tau+\gamma) /(\beta-\alpha)$ then the $\mathrm{HBC}$ case applies with any trust bound $\mathrm{H} \geq \mathrm{G}$. On the other hand, if the prince's cost of crises satisfies $\mathrm{L}<(\delta \mathrm{G}+\alpha \tau+\gamma) /(\beta-\alpha)$ then the SBC case applies at $\mathrm{H}=\mathrm{G}$, but increasing the trust bound $\mathrm{H}$ may cause a switch to the $\mathrm{HBC}$ case.

To illustrate, let us consider examples where, as before, $\alpha=0.1, \beta=0.3, \gamma=1, \delta=0.05$, and $\mathrm{D}=5$, but now $\mathrm{K}=0$. To satisfy the assumption $\alpha \mathrm{L}+\gamma<\beta \mathrm{L}$, we must have $\mathrm{L}>\tau=5$. 
For the lowest possible trust bound $\mathrm{H}=\mathrm{D}$, high effort can never be motivated, and so the prince's total discounted cost must be $\mathrm{W}(\mathrm{D})=\mathrm{D}+\beta \mathrm{L} / \delta=5+6 \mathrm{~L}$. This solution applies with any $\mathrm{H}$ less than $\mathrm{G}$.

Now consider the case of $\mathrm{H}=\mathrm{G}=10$, the smallest credit bound where high effort is possible. For the $\mathrm{HBC}$ case to hold with $\mathrm{H}=\mathrm{G}$, we would need $\mathrm{L} \geq(\delta \mathrm{G}+\alpha \tau+\gamma) /(\beta-\alpha)=10$. So with $\mathrm{L} \geq 10$ and $\mathrm{H}=\mathrm{G}$ here, the new governor would be started right away with credit $\mathrm{G}$, and would always be expected to exert high effort, but would be dismissed with probability $\tau / \mathrm{G}=$ 0.5 whenever a crisis occurs. For any L between 5 and 10, the SBC case holds, and so the governor would start at credit D, and she would be expected to exert low effort until her credit grew to $\mathrm{u}=\mathrm{G}$ after a growth period of length $\mathrm{LN}(\mathrm{G} / \mathrm{D}) / \delta=13.86$, but then she would be paid at rate $\delta \mathrm{G}+\alpha \tau+\gamma=2$ for high effort until the next crisis (after which her pay and high efforts would again be suspended for another time interval of length 13.86). With such an SBC incentive plan, the governor would never be dismissed.

Now let the crisis cost be $\mathrm{L}=9$, keeping other parameters as above. Then a low trust bound $\mathrm{H}$ near $\mathrm{G}=10$ would put us in the $\mathrm{SBC}$ case, and so the governor would never be dismissed. But increasing the parameter $\mathrm{H}$ would reduce $\mathrm{V}(\mathrm{D})$ from Theorem 3 . When $\mathrm{H}>12.4$ with $L=9$, the expected cost $V(D)$ falls below $(\beta L-\alpha L-\gamma) / \delta$, and then the hard budget constraint applies. That is, when the trust bound $\mathrm{H}$ is greater than 12.4 , governors are started at the initial credit level G, are always expected to exert high effort, and have a positive probability of dismissal whenever their credit drops below $G$ after a crisis. Thus we see that increasing the upper bound on what the prince can credibly promise to the governors can switch the optimal incentive policy from one characterized by a soft budget constraint to one characterized by a hard budget constraint.

\section{[Insert Figure 4 about here]}

Figure 4 shows where the soft and hard budget constraints policies are optimal for different $(\mathrm{L}, \mathrm{H})$ pairs, keeping the other parameters kept as above. For any L between 7.9 and 10, an increase of the trust bound $\mathrm{H}$ above $\mathrm{G}=10$ can cause the optimal policy to switch from soft to hard budget constraint in this example.

When the soft budget constraint becomes optimal for the prince here, it is not caused by any intrinsic cost for the prince to dismiss a governor (as in Kornai, Maskin, and Roland, 2003). Instead, the soft budget constraint is caused here by the prince's short-term benefit from 
dismissing a governor who is owed a large credit. When the prince is less able to resist this short-term temptation to dismiss high-credit governors, the trust bound $\mathrm{H}$ becomes low, then the soft budget constraint can become optimal. When the trust bound is too low, governors' credits cannot be far from the range where each crisis would require a risk of dismissal under the hard budget constraint, and so the hard-budget-constraint policy would entail too many dismissals, which become costly for the prince when they are anticipated by the governors. Thus, the center's temptation to dismiss high-credit governors can be a reason for avoiding difficult judgments and reducing performance standards with a soft-budget-constraint policy.

\section{Other assumptions about the prince's circle of trust}

The analysis here has considered the prince's problem of filling a single governor's office, where the characteristics of this office (the moral-hazard opportunities associated with it) are given exogenously. Such governorships are assumed here to be uniquely powerful positions in society, because the wealth that a governor can earn $(G=D+\gamma /(\beta-\alpha))$ is substantially larger than what anyone could possibly earn outside of these offices (K). Our model could be appropriate for a state that is naturally partitioned into a given set of provinces, each of which requires an official to locally represent the authority of the state. But the validity of our assumptions may become weaker in a world with many different offices.

For example, suppose instead that there are so many governorships that vacancies in these offices occur frequently. Under this assumption, when a governor deserves some $\mathrm{u}-\tau<\mathrm{G}$ after a crisis, the governor could be temporarily retired or furloughed, and the required expectation $u-\tau$ could be derived from her prospects of returning to high office when some future vacancy occurs. For such a plan to be feasible, the expected discount factor after the furlough period $\mathrm{E}\left(\mathrm{e}^{-\delta \mathrm{T}}\right)$ must match the probability of reinstatement $(\mathrm{u}-\tau) / \mathrm{G}$ in the randomized fair trials of our plan from sections 3 and 4 . Under this furlough plan, however, the prince must be constrained to respect the right of a former governor to return to high office, after an appropriate period in disgrace. Ex post, however, the prince would prefer to disavow his implicit debt to the disgraced former governor and instead sell the office to a new candidate for $\mathrm{K}$.

The prince could do even better when there are many different offices with greater and lesser opportunities for moral hazard. For example, suppose that a lower office exists where the lesser opportunities for corruption can be deterred by promising future rewards that are worth $\mathrm{K}$ 
when the official serves correctly. The prince would lose nothing by selling this office to an outside candidate for the amount $\mathrm{K}$. But then suppose that, instead of paying the lower official, the prince simply increased her credit over time until the official's credit reached the amount $G$ that a new governor needs. Then the prince could promote this official to governor without loss. In this state, since each promoted candidate pays the full value of her office, the prince would have no cost of turnover, and so the prince would derive no advantages from increasing the credit bound $\mathrm{H}$ above $\mathrm{G}$ and decreasing the rate of turnover below $\alpha$. For this plan to work, however, the lower officials must share the higher officials' confidence that the prince will honor debts of size $\mathrm{G}$ or more to them. In effect, the lower officials must be members of the same circle of trust with the high officials.

Of course, if everybody could trust the prince to faithfully repay debts of size G or greater, then the prince could simply offer a savings plan where citizens would be invited to deposit their private wealth $\mathrm{K}$ along with all subsequent interest on these deposits, until they accumulate enough to pay the full value $\mathrm{G}$ for a governorship. Such savings accounts would invalidate our initial assumption of a gap between the greatest value $\mathrm{K}$ that common citizens can accumulate and the least value $\mathrm{G}$ that a governor must expect. But in this alternative world, the prince would be tempted to expropriate the citizens' deposits, just as he would prefer to disavow his implicit debt to an individual who has served without pay in a lower office.

Thus, the realism of our model depends on recognizing that, in many societies, individuals may have very different abilities to defend valuable claims against the state. Throughout history, many rulers have been able to hold political power without trust or support from the great mass of common people, but no ruler can hold power for long without the trust and support of the governors and captains who are the principal instruments of his power. That is, any successful political leader must be able to credibly promise large future rewards (at least $\mathrm{G}$ here) to the high officials of his government, but the same leader may be unable to credibly restrain his government from cheating common citizens of much smaller amounts. Indeed, the leader's need to maintain faith with his high officials may prevent him from punishing them for expropriating commoners' assets, and the expected income from such expropriations from commoners may be counted as part of the officials' compensation. In such a situation, as our model assumes, the leader would be able to guarantee large debts $\mathrm{H}$ to the elite members of his inner circle, while others in the population could not hold assets worth more than $\mathrm{K}$ without 
serious risk of expropriation, where $\mathrm{K}<\mathrm{G}<\mathrm{H}$.

\section{Conclusions}

We have considered a simple dynamic moral-hazard agency model to emphasize the crucial problems of judging and punishing high officials of the state. For high officials to be deterred from abusing their power, they must be confident that loyal service will bring great expected rewards. We have seen that an inability of the state to credibly promise sufficiently great rewards for good service may sometimes cause the state to demand less of its agents when their credit is low, forgiving costly losses that are evidence of low effort or corruption, as in Kornai's soft budget constraint. When the stakes are high enough to justify a system of hard budget constraints, some punishment of loyal hard-working officials may be unavoidable because monitoring is imperfect. But such punishments raise a fundamental problem of trust at the center of the state because, ex post, penalties reduce the debt of the state, and dismissals can become profitable opportunities for the head of state to resell valuable offices. The need to apply a randomized punishment strategy, to deter rebellions, requires that the process of judging high officials must be monitored in detail. Thus, we have argued that a political leader needs to guarantee the credibility of his incentive plan for high officials by a constitutional system in which high officials cannot be punished without a trial that is witnessed by others in an institutionalized court or council.

When these institutionalized protections apply only to the small governing elite, so that people outside this elite cannot accumulate the wealth that high officials must be guaranteed, then the leader's optimal incentive plan should minimize the expected turnover of high officials. Such minimization of turnover can be accomplished by deferring compensation and increasing the leader's debt to his officials, so that most crises can be penalized by temporarily suspending some payments on this debt without actually dismissing the responsible official. Thus, moralhazard problems can provide a positive incentive for political leaders to accumulate the largest possible debts to their officials, even when leaders and officials discount the future at the same rate. In the long run, however, this accumulation of such debts will create an elite aristocracy that holds large expensive claims on the state.

Such accumulated debts of aristocratic privileges can ultimately weaken the state by decreasing the resources that it can apply to defend itself against other challenges. But these 
institutionalized debts can be repudiated only when a new dynasty begins with a leader who is not bound by any inherited promises of predecessors to their governing elite. Thus, our model may offer some explanation of traditional dynastic declines in history. Such declines could, however, call into question our simplifying assumption that the prince's trust bound $\mathrm{H}$ is parametrically constant over time. In a more realistic (but much more complicated) model, the trust bound $\mathrm{H}$ might decrease as the prince's debts to other agents grow.

Notice that the rationale here for vesting high offices in the members of an elite aristocracy is not based on any assumption of innate inequality among individuals. Indeed, our analysis implicitly assumed an innate equality among individuals, because we have not considered any possibility that a policy of recruiting broadly from the mass of poor commoners might yield more capable officials than the leader can find among his trusted inner circle of aristocrats. In our analysis, elitism results instead from a scarcity of social trust: trust by a leader that his agents will not abuse delegated powers for short-term private gain, and trust by agents that their leader will actually pay them deferred rewards for long years of loyal service.

In essence, the expected rewards that must be associated with high offices make them valuable assets, for which qualified candidates would be willing to pay ex ante, to the extent that they have the means. But these expected rewards are also a liability of the state, and the leader of the state would profit ex post by repudiating such liabilities. So high officials must be recognized as having acquired valuable rights to their offices, and these rights require institutional protection and legal enforcement, like any other property rights. People generally look to the state for enforcement of property rights, but in this case we are considering the enforcement of debts owed by the leader of the state himself. The key to enforcement in this case may be the observation that the leader cannot get loyal service from his high officials if they lose their trust that he will fulfill his promises. If high officials have a shared sense of identity, then the wrongful dismissal of any one of them can cause others to lose trust in the leader. So when there is any question about whether a high official has been wrongly dismissed by the leader, the jury for deciding this question can be found among the other high officials. Thus, the leader's essential credibility can be maintained by instituting a court or council where any judgment against a high official will be scrutinized by others in their privileged class.

Throughout history, successful governments have developed such institutions to serve this essential function of regulating punishment of powerful government agents. The Hittite 
Panku council, the Roman Senate, and the English Exchequer are just a few examples that we have noted here. The importance of the medieval Exchequer can be particularly appreciated when we contrast it with the centrifugal forces of feudalism in the same period. The king's ability to exercise authority throughout the realm depended critically on the sheriffs' confidence that loyal service would earn the king's reward, but a policy of never punishing sheriffs would constitute surrender to feudal disintegration of the state. Strong centralized government required credible guarantees that punishment of local government agents would occur only in carefully limited circumstances situations, and such guarantees required formal institutions to protect the agents' rights. From this perspective, we can also see how the subsequent development of parliamentary representation in England (from the thirteenth century) could further strengthen

royal government, by enabling kings to credibly guarantee privileges to a broader class of local government agents than could be practically assembled at court (Coss, 2005, ch 7).

In the absence of such institutional guarantees, when governors and local commanders lose trust that their ruler will treat them fairly, the results can be disastrous for the state, as the Hittite king Telipinu warned 3500 years ago. For one example, the collapse of the Ming dynasty in China began in 1630 when the Ming emperor was seen to unjustly execute his commander against the Manchus, Yuan Chonghuan, whose string of celebrated victories had been broken by one reversal. Thereafter, other Chinese commanders regularly defected to the Manchus, who soon replaced the Ming as rulers of China (Mote, 1999, ch 30). The moral-hazard constraints in our model are a simple stylized representation of the standards of expected behavior that a leader must satisfy to avoid such disasters and maintain the state.

\section{Proofs}

Proof of Theorem 1. Notice first that the optimal value function V(u) always is weakly increasing in $u$, because increasing $u$ can only tighten constraint (1) in the minimization (7). Because $\mathrm{V}$ is weakly increasing, the optimal value with a new governor must be

$$
\begin{aligned}
\mathrm{v}_{0}= & \min _{\mathrm{y}, \mathrm{r}, \mathrm{z}}-\mathrm{K}+\varepsilon \mathrm{y}+(1-\varepsilon \alpha) \mathrm{V}(\mathrm{r})+\varepsilon \alpha \mathrm{V}(\mathrm{r}-\mathrm{z}) \\
& \quad \text { subject to } \mathrm{z} \geq \tau, \mathrm{r}-\mathrm{z} \geq \mathrm{D}, \mathrm{r} \leq \mathrm{H}, \mathrm{y} \geq 0 \\
= & (1-\varepsilon \alpha) \mathrm{V}(\mathrm{G})+\varepsilon \alpha \mathrm{V}(\mathrm{D})-\mathrm{K},
\end{aligned}
$$

with the minimum achieved by $\mathrm{y}=0, \mathrm{r}-\mathrm{z}=\mathrm{D}$, and $\mathrm{r}=\mathrm{D}+\tau=\mathrm{G}$, as in condition (8).

For any bounded function $\hat{\mathrm{V}}$ on $[\mathrm{D}, \mathrm{H}]$, let 


$$
\theta_{0}(\hat{V})=(1-\varepsilon \alpha) \hat{V}(G)+\varepsilon \alpha \hat{V}(D)-K,
$$

and let $\Xi(\hat{V})$ denote the function defined by

$$
\begin{gathered}
\Xi(\hat{\mathrm{V}})(\mathrm{u})=\min _{\mathrm{y}, \mathrm{q}, \mathrm{r}, \mathrm{z}}\left\{\varepsilon \mathrm{y}+\mathrm{q} \theta_{0}(\hat{\mathrm{V}})+(1-\mathrm{q})[(1-\varepsilon \alpha) \hat{\mathrm{V}}(\mathrm{r})+\varepsilon \alpha \hat{\mathrm{V}}(\mathrm{r}-\mathrm{z})]\right\} /(1+\varepsilon \delta) \\
\text { subject to } \mathrm{z} \geq \tau, \mathrm{r}-\mathrm{z} \geq \mathrm{D}, \mathrm{r} \leq \mathrm{H}, \mathrm{y} \geq 0,0 \leq \mathrm{q} \leq 1, \\
\text { and } \varepsilon \mathrm{y}+(1-\mathrm{q})[(1-\varepsilon \alpha) \mathrm{r}+\varepsilon \alpha(\mathrm{r}-\mathrm{z})] \geq(1+\varepsilon \delta) \mathrm{u},
\end{gathered}
$$

With $\varepsilon \delta>0, \Xi$ is a contraction mapping, satisfying

$$
\max _{\mathrm{u} \in[\mathrm{D}, \mathrm{H}]}|\Xi(\hat{\mathrm{V}})(\mathrm{u})-\Xi(\hat{\mathrm{V}})(\mathrm{u})| \leq \max _{\mathrm{u} \in[\mathrm{D}, \mathrm{H}]}|\hat{\mathrm{V}}(\mathrm{u})-\hat{\mathrm{V}}(\mathrm{u})| /(1+\varepsilon \delta) .
$$

So there will be a unique bounded fixed point $\mathrm{V}$ that satisfies $\mathrm{V}=\Xi(\mathrm{V})$, and this unique fixedpoint $\mathrm{V}$ must be the optimal value function $\mathrm{V}$ satisfying condition $(7)$ at all $\mathrm{u}$ with $\mathrm{v}_{0}=\theta_{0}(\mathrm{~V})$. The contraction-mapping property implies that the value function $\mathrm{V}$ could be computed from any initial guess $\hat{\mathrm{V}}$ by iteratively applying $\Xi$ to get $\mathrm{V}(\mathrm{u})=\lim _{\mathrm{n} \rightarrow \infty} \Xi^{\mathrm{n}}(\hat{\mathrm{V}})(\mathrm{u})$.

We now claim that, if $\hat{\mathrm{V}}$ is a convex function on $[\mathrm{D}, \mathrm{H}]$ that has slopes always between $\mathrm{K} /(\mathrm{G}-\varepsilon \alpha \tau)$ and $1, \Xi(\hat{\mathrm{V}})$ is also convex and has slopes always between $\mathrm{K} /(\mathrm{G}-\varepsilon \alpha \tau)$ and 1 . This claim implies that, if we start from an initial guess that is convex and has slopes between $\mathrm{K} /(\mathrm{G}-\varepsilon \alpha \tau)$ and 1 (such as the identity function $\hat{\mathrm{V}}(\mathrm{u})=\mathrm{u})$, then all $\Xi^{\mathrm{n}}(\hat{\mathrm{V}})$ and the limiting optimal value $\mathrm{V}$ will be convex and have slopes always between $\mathrm{K} /(\mathrm{G}-\varepsilon \alpha \tau)$ and 1 . In the rest of this proof, we will prove this claim and show that it implies the optimal policies described in conditions Theorem 1.

So henceforth assume that $\hat{\mathrm{V}}$ is a convex function on $[\mathrm{D}, \mathrm{H}]$ that has slopes always between $\mathrm{K} /(\mathrm{G}-\varepsilon \alpha \tau)$ and 1. Recall $\mathrm{G}_{\varepsilon}=(\mathrm{G}-\varepsilon \alpha \tau) /(1+\varepsilon \delta)$ and $\mathrm{H}_{\varepsilon}=(\mathrm{H}-\varepsilon \alpha \tau) /(1+\varepsilon \delta)$.

First consider any $\mathrm{u}$ in $\left[\mathrm{G}_{\varepsilon}, \mathrm{H}_{\varepsilon}\right]$. For the minimization that defines $\Xi(\hat{V})(\mathrm{u})$, a Lagrangean function with multiplier $\lambda$ for the promise-keeping constraint (1) can be written as follows:

$$
\begin{aligned}
\{\varepsilon y+ & \left.\mathrm{q} \theta_{0}(\hat{\mathrm{V}})+(1-\mathrm{q})[(1-\varepsilon \alpha) \hat{\mathrm{V}}(\mathrm{r})+\varepsilon \alpha \hat{\mathrm{V}}(\mathrm{r}-\mathrm{z})]\right\} /(1+\varepsilon \delta) \\
& +\lambda\{(1+\varepsilon \delta) \mathrm{u}-\varepsilon \mathrm{y}-(1-\mathrm{q})[(1-\varepsilon \alpha) \mathrm{r}+\varepsilon \alpha(\mathrm{r}-\mathrm{z})]\} .
\end{aligned}
$$

Let the Lagrange multiplier be

$$
\lambda=\left[(1-\varepsilon \alpha) \hat{\mathrm{V}}^{\prime}(\mathrm{u}+\varepsilon \delta+\varepsilon \alpha \tau)+\varepsilon \alpha \hat{\mathrm{V}}^{\prime}(\mathrm{u}+\varepsilon \delta \mathrm{u}+\varepsilon \alpha \tau-\tau)\right] /(1+\varepsilon \delta) .
$$

(Here the derivative $\hat{\mathrm{V}}^{\prime}$ can be taken to be the right-hand slope of $\hat{\mathrm{V}}$ for small increases, which is well defined for the convex function $\hat{V}$ even where it has a nondifferentiable kink.) Given any $q$ between 0 and 1, this Lagrangean is convex in $y, r$, and $z$, and it is minimized subject to the linear constraints $\mathrm{y} \geq 0$ and $\mathrm{z} \geq \tau$ by letting

$$
\mathrm{y}=0, \mathrm{z}=\tau \text {, and } \mathrm{r}=\mathrm{u}+\varepsilon \delta \mathrm{u}+\varepsilon \alpha \tau \text {. }
$$


First-order optimality conditions can be verified at this solution, given that $\hat{\mathrm{V}}^{\prime}$ is increasing and always between 0 and 1 . With these optimal values of $(y, r, z)$, the Lagrangean reduces to

$$
\begin{aligned}
\left\{\mathrm{q} \theta_{0}(\hat{\mathrm{V}})\right. & +(1-\mathrm{q})[(1-\varepsilon \alpha) \hat{\mathrm{V}}(\mathrm{r})+\varepsilon \alpha \hat{\mathrm{V}}(\mathrm{r}-\tau)]\} /(1+\varepsilon \delta)+ \\
& +\{(1+\varepsilon \delta) \mathrm{u}-(1-\mathrm{q})(\mathrm{r}-\varepsilon \alpha \tau)\}\left[(1-\varepsilon \alpha) \hat{\mathrm{V}}^{\prime}(\mathrm{r})+\varepsilon \alpha \hat{\mathrm{V}}^{\prime}(\mathrm{r}-\tau)\right] /(1+\varepsilon \delta) .
\end{aligned}
$$

This is an increasing function of $q$ because the convexity of $\hat{V}$ and the bounds on its slope imply:

$$
\begin{aligned}
& \theta_{0}(\hat{\mathrm{V}})- {[(1-\varepsilon \alpha) \hat{\mathrm{V}}(\mathrm{r})+\varepsilon \alpha \hat{\mathrm{V}}(\mathrm{r}-\tau)]+(\mathrm{r}-\varepsilon \alpha \tau)\left[(1-\varepsilon \alpha) \hat{\mathrm{V}}^{\prime}(\mathrm{r})+\varepsilon \alpha \hat{\mathrm{V}}^{\prime}(\mathrm{r}-\tau)\right] } \\
&= \theta_{0}(\hat{\mathrm{V}})-[(1-\varepsilon \alpha) \hat{\mathrm{V}}(\mathrm{r})+\varepsilon \alpha \hat{\mathrm{V}}(\mathrm{r}-\tau)]-(\mathrm{G}-\mathrm{r})\left[(1-\varepsilon \alpha) \hat{\mathrm{V}}^{\prime}(\mathrm{r})+\varepsilon \alpha \hat{\mathrm{V}}^{\prime}(\mathrm{r}-\tau)\right] \\
&+(\mathrm{G}-\varepsilon \alpha \tau)\left[(1-\varepsilon \alpha) \hat{\mathrm{V}}^{\prime}(\mathrm{r})+\varepsilon \alpha \hat{\mathrm{V}}^{\prime}(\mathrm{r}-\tau)\right] \\
& \geq \theta_{0}(\hat{\mathrm{V}})-[(1-\varepsilon \alpha) \hat{\mathrm{V}}(\mathrm{G})+\varepsilon \alpha \hat{\mathrm{V}}(\mathrm{G}-\tau)]+(\mathrm{G}-\varepsilon \alpha \tau)\left[(1-\varepsilon \alpha) \hat{\mathrm{V}}^{\prime}(\mathrm{r})+\varepsilon \alpha \hat{\mathrm{V}}^{\prime}(\mathrm{r}-\tau)\right] \\
& \geq-\mathrm{K}+(\mathrm{G}-\varepsilon \alpha \tau) \mathrm{K} /(\mathrm{G}-\varepsilon \alpha \tau)=0 .
\end{aligned}
$$

So the reduced Lagrangean is minimized over $\mathrm{q} \geq 0$ by letting $\mathrm{q}=0$. These optimal values satisfy all constraints and satisfy the promise-keeping constraint with equality. Thus, for this case of $\mathrm{G}_{\varepsilon} \leq \mathrm{u} \leq \mathrm{H}_{\varepsilon}$, the optimal policy is as specified in condition (11) of the theorem. This optimal solution yields

$$
\Xi(\hat{\mathrm{V}})(\mathrm{u})=[(1-\varepsilon \alpha) \hat{\mathrm{V}}(\mathrm{u}+\varepsilon \delta \mathrm{u}+\varepsilon \alpha \tau)+\varepsilon \alpha \hat{\mathrm{V}}(\mathrm{u}+\varepsilon \delta \mathrm{u}+\varepsilon \alpha \tau-\tau)]\} /(1+\varepsilon \delta) .
$$

The slope is

$$
\Xi(\hat{\mathrm{V}})^{\prime}(\mathrm{u})=(1-\varepsilon \alpha) \hat{\mathrm{V}}^{\prime}(\mathrm{u}+\varepsilon \delta \mathrm{u}+\varepsilon \alpha \tau)+\varepsilon \alpha \hat{\mathrm{V}}^{\prime}(\mathrm{u}+\varepsilon \delta \mathrm{u}+\varepsilon \alpha \tau-\tau),
$$

which is increasing in $\mathrm{u}$ and always between $\mathrm{K} /(\mathrm{G}-\varepsilon \alpha \tau)$ and 1 , given these properties for $\hat{\mathrm{V}}^{\prime}$.

For the case of $\mathrm{H}_{\varepsilon}<\mathrm{u} \leq \mathrm{H}$, the above argument fails because $\mathrm{u}+\varepsilon \delta \mathrm{u}+\varepsilon \alpha \tau>\mathrm{H}$. But in this case we can let the multiplier of the promise-keeping constraint be $\lambda=1 /(1+\varepsilon \delta)$, so that the Lagrangean becomes

$$
\begin{aligned}
\{\varepsilon y+ & q \theta_{0}(\hat{V})+(1-q)[(1-\varepsilon \alpha) \hat{V}(r)+\varepsilon \alpha \hat{V}(r-z)] \\
+ & {[(1+\varepsilon \delta) u-\varepsilon y-(1-q)(r-\varepsilon \alpha z)]\} /(1+\varepsilon \delta) . }
\end{aligned}
$$

Then for any $q$ in $[0,1]$, sufficient first-order conditions for minimizing the Lagrangean over $(\mathrm{y}, \mathrm{r}, \mathrm{z})$ subject to $\mathrm{r} \leq \mathrm{H}$ and $\mathrm{z} \geq \tau$ are satisfied by

$$
\varepsilon y=u+\varepsilon \delta \mathrm{u}+\varepsilon \alpha \tau-\mathrm{H}>0, \mathrm{r}=\mathrm{H} \text {, and } \mathrm{z}=\tau,
$$

because $\hat{\mathrm{V}}$ is convex and its slope $\hat{\mathrm{V}}^{\prime}$ is always between 0 and 1 . Then the Lagrangean is increasing in $\mathrm{q}$, because, with the slope of $\hat{\mathrm{V}}$ bounded above by 1 , we have

$$
\begin{aligned}
& \theta_{0}(\hat{\mathrm{V}})- {[(1-\varepsilon \alpha) \hat{\mathrm{V}}(\mathrm{H})+\varepsilon \alpha \hat{\mathrm{V}}(\mathrm{H}-\tau)]+(\mathrm{H}-\varepsilon \alpha \tau) } \\
&=-\mathrm{K}+[(1-\varepsilon \alpha) \hat{\mathrm{V}}(\mathrm{G})+\varepsilon \alpha \hat{\mathrm{V}}(\mathrm{G}-\tau)]-[(1-\varepsilon \alpha) \hat{\mathrm{V}}(\mathrm{H})+\varepsilon \alpha \hat{\mathrm{V}}(\mathrm{H}-\tau)]+\mathrm{H}-\varepsilon \alpha \tau \\
& \geq-\mathrm{K}+(\mathrm{G}-\mathrm{H})+\mathrm{H}-\varepsilon \alpha \tau=\mathrm{G}-\varepsilon \alpha \tau-\mathrm{K}>0 .
\end{aligned}
$$


So the reduced Lagrangean is again minimized over $\mathrm{q} \geq 0$ by letting $\mathrm{q}=0$, and these optimal values also satisfy the promise-keeping constraint with equality. Thus, for this case of $\mathrm{u}>\mathrm{H}_{\varepsilon}$, the optimal policy is also as specified in condition (11) of the theorem. This solution yields

$$
\Xi(\hat{\mathrm{V}})(\mathrm{u})=[\mathrm{u}+\varepsilon \delta \mathrm{u}+\varepsilon \alpha \tau-\mathrm{H}+(1-\varepsilon \alpha) \hat{\mathrm{V}}(\mathrm{H})+\varepsilon \alpha \hat{\mathrm{V}}(\mathrm{H}-\tau)]\} /(1+\varepsilon \delta) .
$$

The slope is $\Xi(\hat{V})^{\prime}(u)=1$ for any such $u>H_{\varepsilon}$.

For the case of $\mathrm{u}<\mathrm{G}_{\varepsilon}$, let the Lagrange multiplier be $\lambda=\mathrm{K} /[(\mathrm{G}-\varepsilon \alpha \tau)(1+\varepsilon \delta)]$, so that the Lagrangean becomes

$$
\begin{aligned}
\{\varepsilon y+ & q \theta_{0}(\hat{V})+(1-q)[(1-\varepsilon \alpha) \hat{V}(r)+\varepsilon \alpha \hat{V}(r-z)] \\
& +[K /(G-\varepsilon \alpha \tau)][(1+\varepsilon \delta) u-\varepsilon y-(1-q)(1-\varepsilon \alpha) r-(1-q) \varepsilon \alpha(r-z)]\} /(1+\varepsilon \delta) .
\end{aligned}
$$

For any $q$ between 0 and 1 , the Lagrangean is minimized over $(y, r, z)$ subject to $y \geq 0, r-z \geq D$, and $\mathrm{r} \geq \mathrm{G}$, by letting

$$
\mathrm{y}=0, \mathrm{r}-\mathrm{z}=\mathrm{D}, \mathrm{r}=\mathrm{G},
$$

because the slope of $\hat{V}$ always satisfies $1 \geq \hat{V}^{\prime} \geq K /(G-\varepsilon \alpha \tau)$. Then the Lagrangean reduces to

$$
\begin{aligned}
& \left\{\mathrm{q} \theta_{0}(\hat{\mathrm{V}})+(1-\mathrm{q})[(1-\varepsilon \alpha) \hat{\mathrm{V}}(\mathrm{G})+\varepsilon \alpha \hat{\mathrm{V}}(\mathrm{D})]\right. \\
& +[\mathrm{K} /(\mathrm{G}-\varepsilon \alpha \tau)][\mathrm{u}+\varepsilon \delta \mathrm{u}-(1-\mathrm{q})(\mathrm{G}-\varepsilon \alpha \tau)]\} /(1+\varepsilon \delta) \\
& =\{-\mathrm{qK}+(1-\varepsilon \alpha) \hat{\mathrm{V}}(\mathrm{G})+\varepsilon \alpha \hat{\mathrm{V}}(\mathrm{D}) \\
& \quad+[\mathrm{K} /(\mathrm{G}-\varepsilon \alpha \tau)][\mathrm{u}+\varepsilon \delta \mathrm{u}+\varepsilon \alpha \tau-\mathrm{G}+\mathrm{q}(\mathrm{G}-\varepsilon \alpha \tau)]\} /(1+\varepsilon \delta),
\end{aligned}
$$

which is independent of q. So we can minimize the Lagrangean and satisfy the promise-keeping constraint (1) with equality by letting

$$
\mathrm{q}=1-(\mathrm{u}+\varepsilon \delta \mathrm{u}) /(\mathrm{G}-\varepsilon \alpha \tau)=1-\mathrm{u} / \mathrm{G}_{\varepsilon} .
$$

Thus, for $u<G_{\varepsilon}$, an optimal solution satisfies condition (9) in the theorem. This solution yields

$$
\Xi(\hat{\mathrm{V}})(\mathrm{u})=\left\{-\left(1-\mathrm{u} / \mathrm{G}_{\varepsilon}\right) \mathrm{K}+(1-\varepsilon \alpha) \hat{\mathrm{V}}(\mathrm{G})+\varepsilon \alpha \hat{\mathrm{V}}(\mathrm{D})\right\} /(1+\varepsilon \delta),
$$

The slope is $\Xi(\hat{V})^{\prime}(u)=K /(G-\varepsilon \alpha \tau)$ for any such $u<G_{\varepsilon}$.

Our characterizations of the slopes $\Xi(\hat{\mathrm{V}})^{\prime}(\mathrm{u})$ verify the claim that $\Xi(\hat{\mathrm{V}})$ is convex and has slopes between $\mathrm{K} /(\mathrm{G}-\varepsilon \alpha \tau)$ and 1 , for all $\mathrm{u}$ in $[\mathrm{D}, \mathrm{H}]$, when $\hat{V}$ has these properties. So the fixedpoint $\mathrm{V}$ has these properties, and the optimal solutions are as summarized in Theorem 1. Q.E.D.

Proof of Theorem 3. We have seen that the derivative $\Psi^{\prime}$ increases discontinuously at G, from $\Psi^{\prime}(\mathrm{u})=0$ when $\mathrm{u}<\mathrm{G}$ to $\Psi^{\prime}(\mathrm{G})=\delta /(\delta \mathrm{G}+\alpha \tau)>0$. At any $\mathrm{u} \geq \mathrm{G}$, differentiating (19) yields 


$$
\begin{gathered}
\Psi^{\prime \prime}(\mathrm{u})=\left[(\delta+\alpha) \Psi^{\prime}(\mathrm{u})-\alpha \Psi^{\prime}(\mathrm{u}-\tau)\right] /(\delta \mathrm{u}+\alpha \tau) \\
-[(\delta+\alpha) \Psi(\mathrm{u})-\alpha \Psi(\mathrm{u}-\tau)] \delta /(\delta \mathrm{u}+\alpha \tau)^{2} \\
=\left[(\delta+\alpha) \Psi^{\prime}(\mathrm{u})-\alpha \Psi^{\prime}(\mathrm{u}-\tau)-\delta \Psi^{\prime}(\mathrm{u})\right] /(\delta \mathrm{u}+\alpha \tau) \\
=\alpha\left[\Psi^{\prime}(\mathrm{u})-\Psi^{\prime}(\mathrm{u}-\tau)\right] /(\delta \mathrm{u}+\alpha \tau) .
\end{gathered}
$$

This formula yields $\Psi^{\prime \prime}(\mathrm{G})>0$, because $\Psi^{\prime}(\mathrm{G})=\delta /(\delta \mathrm{G}+\alpha \tau)>\Psi^{\prime}(\mathrm{G}-\tau)=0$. If $\Psi^{\prime \prime}(\mathrm{u})$ were not always strictly positive when $\mathrm{u} \geq \mathrm{G}$, then there would exist some smallest $\hat{\mathrm{u}} \geq \mathrm{G}$ such that $\Psi^{\prime \prime}(\hat{\mathrm{u}})=0$; but then $\Psi^{\prime \prime}(\mathrm{u})>0$ for all smaller u would imply $\Psi^{\prime}(\hat{\mathrm{u}})>\Psi^{\prime}(\hat{\mathrm{u}}-\tau)$, yielding the contradiction

$$
\Psi^{\prime \prime}(\hat{\mathrm{u}})=\alpha\left[\Psi^{\prime}(\hat{\mathrm{u}})-\Psi^{\prime}(\hat{\mathrm{u}}-\tau)\right] /(\delta \hat{\mathrm{u}}+\alpha \tau)>0 .
$$

So $\Psi^{\prime \prime}(\mathrm{u})>0$ for all $\mathrm{u} \geq \mathrm{G}$. Thus, $\Psi^{\prime}(\mathrm{u})$ is strictly increasing and positive when $\mathrm{u} \geq \mathrm{G}$, and $\Psi(\mathrm{u})$ is a convex function of $u$.

But the initial conditions and differential equation (18)-(19) that uniquely characterize $\Psi(\mathrm{u})$ are satisfied by

$$
\Psi(\mathrm{u})=(\mathrm{V}(\mathrm{u})-\mathrm{uK} / \mathrm{G}) / \mathrm{V}(0),
$$

because $\mathrm{V}$ satisfies conditions (14)-(15). Then condition (16), $\mathrm{V}^{\prime}(\mathrm{H})=1$, implies

$$
\Psi^{\prime}(\mathrm{H})=(1-\mathrm{K} / \mathrm{G}) / \mathrm{V}(0) \text {, and so } \mathrm{V}(0)=(1-\mathrm{K} / \mathrm{G}) / \Psi^{\prime}(\mathrm{H}) \text {. }
$$

Thus, the function $\mathrm{V}$ can be computed from $\Psi$ by the formulas

$$
\mathrm{V}(\mathrm{u})=\mathrm{uK} / \mathrm{G}+\Psi(\mathrm{u}) \mathrm{V}(0)=\mathrm{uK} / \mathrm{G}+\Psi(\mathrm{u})(1-\mathrm{K} / \mathrm{G}) / \Psi^{\prime}(\mathrm{H}), \forall \mathrm{u} \in[0, \mathrm{H}] . \quad \text { Q.E.D }
$$

Proof of Theorem 5. In this theorem, $\mathbf{u}$ denotes a random credit drawn from the stationary distribution F.

We first prove that the stationary cumulative distribution $\mathrm{F}$ satisfies the following equation, for any w in the interval $[\mathrm{G}, \mathrm{H}]$ :

$$
\int_{\mathrm{u} \in[\mathrm{G}, \mathrm{w})} \delta \mathrm{u} d \mathrm{~F}(\mathrm{u})+\int_{\mathrm{u} \in[\mathrm{w}, \mathrm{w}+\tau]} \alpha(\mathrm{u}-\mathrm{w}-\tau) \mathrm{dF}(\mathrm{u})+\int_{\mathrm{u} \in[\mathrm{G}, \mathrm{G}+\tau]} \alpha(\mathrm{G}+\tau-\mathrm{u}) \mathrm{dF}(\mathrm{u})=0 .
$$

To prove (20) for any w, consider the quantity

$$
\mathrm{E}(\min \{0, \mathbf{u}-\mathrm{w}\})=\int_{\mathrm{u} \in[\mathrm{G}, \mathrm{w}]}(\mathrm{u}-\mathrm{w}) \mathrm{dF}(\mathrm{u}) .
$$

With the stationary distribution $\mathrm{F}$, this expected value is constant over time. The left-hand side of (20) is the rate at which this expected value would increase over time, starting with the distribution F. The first integral in (20) is $\mathrm{F}(\mathrm{w}) \mathrm{E}(\delta \mathbf{u} \mid \mathbf{u}<\mathrm{w})$, which is the expected rate of increase of the current governor's credit $\mathbf{u}$ when starting from a state with $\mathbf{u}<\mathrm{w}$. The second integral is the rate at which newly nonzero (negative) values of $\min \{0, \mathbf{u}-\mathrm{w}\}$ are created from a governor with credit above w having a crisis that brings her credit below w. When the governor's 
credit drops below $\mathrm{G}$, credit is raised to $\mathrm{G}$ by either reinstatement or replacement, and the rate of such raises is $\alpha \mathrm{E}(\max \{\mathrm{G}+\tau-\mathbf{u}, 0\})$, the third integral.

Notice that $\delta \mathrm{G} \leq \mathrm{E}(\delta \mathbf{u} \mid \mathbf{u}<\mathrm{w})$, and $\int_{\mathrm{u} \in[\mathrm{w}, \mathrm{w}+\tau]} \alpha(\mathrm{w}+\tau-\mathrm{u}) \mathrm{dF}(\mathrm{u}) \leq \alpha \tau[\mathrm{F}(\mathrm{w}+\tau)-\mathrm{F}(\mathrm{w})]$, and the third integral in equation (20) is nonnegative. Together, these inequalities imply

$$
\mathrm{F}(\mathrm{w}) \delta \mathrm{G} \leq \mathrm{F}(\mathrm{w}) \mathrm{E}(\delta \mathbf{u} \mid \mathbf{u}<\mathrm{w}) \leq \int_{\mathrm{u} \in[\mathrm{w}, \mathrm{w}+\tau]} \alpha(\mathrm{w}+\tau-\mathrm{u}) \mathrm{dF}(\mathrm{u}) \leq \alpha \tau[\mathrm{F}(\mathrm{w}+\tau)-\mathrm{F}(\mathrm{w})],
$$

and thus,

$$
\mathrm{F}(\mathrm{w}) \leq \mathrm{F}(\mathrm{w}+\tau) \alpha \tau /(\delta \mathrm{G}+\alpha \tau), \quad \forall \mathrm{w} \in[\mathrm{G}, \mathrm{H}] .
$$

Notice $\mathrm{F}(\mathrm{w}+\tau)=1$ when $\mathrm{w}+\tau>\mathrm{H}$. So by induction, for any integer $\mathrm{m} \geq 0$,

$$
\text { if } \mathrm{u} \leq \mathrm{H}-\mathrm{m} \tau \text { then } \mathrm{F}(\mathrm{u}) \leq[\alpha \tau /(\delta \mathrm{G}+\alpha \tau)]^{\mathrm{m}+1} .
$$

These bounds imply that, in the stationary distribution, credit $\mathbf{u}$ is unlikely to be far below $\mathrm{H}$, satisfying

$$
\begin{aligned}
\mathrm{E}(\mathrm{H}-\mathbf{u}) & =\int_{\mathrm{u} \in[\mathrm{G}, \mathrm{H}]}(\mathrm{H}-\mathrm{u}) \mathrm{dF}(\mathrm{u})=\int_{\mathrm{u} \in[\mathrm{G}, \mathrm{H}]} \mathrm{F}(\mathrm{u}) \mathrm{du} \\
& \leq \sum_{\mathrm{m}=0}^{\infty} \tau[\alpha \tau /(\delta \mathrm{G}+\alpha \tau)]^{\mathrm{m}+1}=\alpha \tau^{2} /(\delta \mathrm{G}) .
\end{aligned}
$$

Thus $\mathrm{H}-\alpha \tau^{2} /(\delta \mathrm{G}) \leq \mathrm{E}(\mathbf{u})$. Using (21) with $\mathrm{w}=\mathrm{H}$ and using $\mathrm{F}(\mathrm{H}+\tau)=1$, we get

$$
\mathrm{E}(\delta \mathbf{u})=\mathrm{F}(\mathrm{H}) \mathrm{E}(\delta \mathbf{u} \mid \mathbf{u}<\mathrm{H})+[1-\mathrm{F}(\mathrm{H})] \delta \mathrm{H} \leq \alpha \tau[1-\mathrm{F}(\mathrm{H})]+[1-\mathrm{F}(\mathrm{H})] \delta \mathrm{H} .
$$

Thus $\delta \mathrm{H}-\alpha \tau^{2} / \mathrm{G} \leq \mathrm{E}(\delta \mathbf{u}) \leq[1-\mathrm{F}(\mathrm{H})](\delta \mathrm{H}+\alpha \tau)$ and so we get

$$
\left(\delta \mathrm{H}-\alpha \tau^{2} / \mathrm{G}\right) /(\delta \mathrm{H}+\alpha \tau) \leq 1-\mathrm{F}(\mathrm{H}) .
$$

Proof of Theorem 6. The two cases (HBC and SBC) can be unified by the formula

$$
\begin{aligned}
& \mathrm{W}(\mathrm{u})=(1-\mu) \mathrm{u}+\mu \mathrm{V}(\mathrm{u})+(\alpha \mathrm{L}+\gamma) / \delta, \forall \mathrm{u} \geq \mathrm{D}, \text { where } \\
& \mu=\min \{1,(\beta \mathrm{L}-\alpha \mathrm{L}-\gamma) /(\delta \mathrm{V}(\mathrm{D}))\} .
\end{aligned}
$$

In this proof, let us take $\mathrm{W}$ to be defined from $\mathrm{V}$ according to this formula, with $\mu=1$ in the $\mathrm{HBC}$ case, $\mu<1$ in the SBC case. Then we will show that this function $\mathrm{W}$ satisfies the recursive optimality conditions ( $\left.7^{\prime}\right)$ with the optimal policies that are described in the theorem.

To begin, let us derive some useful properties of $\mathrm{W}$ that follow from this formula, using the properties of $\mathrm{V}$ from Theorem $1 . \mathrm{W}(\mathrm{u})$ is convex and has linear segments when $\mathrm{u}>\mathrm{H}_{\varepsilon}$ and when $\mathrm{u}<\mathrm{G}_{\varepsilon}$, because $\mathrm{V}$ has these properties. Above $\mathrm{H}_{\varepsilon}$, the slope of $\mathrm{W}$ is

$$
\mathrm{W}^{\prime}(\mathrm{u})=1-\mu+\mu \mathrm{V}^{\prime}(\mathrm{u})=1 \text { when } \mathrm{u}>\mathrm{H}_{\varepsilon} \text {. }
$$

Convexity of $\mathrm{W}$ then implies $\mathrm{W}^{\prime}(\mathrm{u}) \leq 1$ for all $\mathrm{u}$. When $\mathrm{u}$ is less than $\mathrm{G}_{\varepsilon}, \mathrm{V}(\mathrm{u})$ is constant (as $\mathrm{K}=0$ here), and so the slope of $\mathrm{W}$ is

$$
\mathrm{W}^{\prime}(\mathrm{u})=1-\mu \geq 0 \text { when } \mathrm{u}<\mathrm{G}_{\varepsilon}
$$


and then, with our formulas for $\mu$ and $\mathrm{W}(\mathrm{u})$, we get

$$
\mathrm{W}(\mathrm{u})-\mathrm{uW}^{\prime}(\mathrm{u})=\mu \mathrm{V}(\mathrm{D})+(\alpha \mathrm{L}+\gamma) / \delta \leq \beta \mathrm{L} / \delta \text { when } \forall \mathrm{u}<\mathrm{G}_{\varepsilon} .
$$

This last inequality becomes an equality in the SBC case where $\mu<1$, and so

$$
\mathrm{W}(\mathrm{u})=\mathrm{uW}^{\prime}(\mathrm{u})+\beta \mathrm{L} / \delta=\mathrm{uW}^{\prime}(\mathrm{D})+\beta \mathrm{L} / \delta \text { when } \mu<1 \text { and } \mathrm{u}<\mathrm{G}_{\varepsilon .} .
$$

When $\mathrm{G}_{\varepsilon} \leq \mathrm{u} \leq \mathrm{H}_{\varepsilon}$, the recursion equation (12) for $\mathrm{V}$ give us a similar equation for $\mathrm{W}$ :

$$
\begin{gathered}
(1-\varepsilon \alpha) \mathrm{W}(\mathrm{u}+\varepsilon \delta \mathrm{u}+\varepsilon \alpha \tau)+\varepsilon \alpha \mathrm{W}(\mathrm{u}+\varepsilon \delta \mathrm{u}+\varepsilon \alpha \tau-\tau)+\varepsilon \alpha \mathrm{L}+\varepsilon \gamma \\
=(1-\mu)[(1-\varepsilon \alpha)(\mathrm{u}+\varepsilon \delta \mathrm{u}+\varepsilon \alpha \tau)+\varepsilon \alpha(\mathrm{u}+\varepsilon \delta \mathrm{u}+\varepsilon \alpha \tau-\tau)]+ \\
\quad+\mu[(1-\varepsilon \alpha) \mathrm{V}(\mathrm{u}+\varepsilon \delta \mathrm{u}+\varepsilon \alpha \tau)+\varepsilon \alpha \mathrm{V}(\mathrm{u}+\varepsilon \delta \mathrm{u}+\varepsilon \alpha \tau-\tau)] \\
\quad+(\alpha \mathrm{L}+\gamma) / \delta+\varepsilon(\alpha \mathrm{L}+\gamma) \\
=(1-\mu)(\mathrm{u}+\varepsilon \delta \mathrm{u})+\mu(1+\varepsilon \delta) \mathrm{V}(\mathrm{u})+(1+\varepsilon \delta)(\alpha \mathrm{L}+\gamma) / \delta \\
=(1+\varepsilon \delta) \mathrm{W}(\mathrm{u}) \text { when } \mathrm{G}_{\varepsilon} \leq \mathrm{u} \leq \mathrm{H}_{\varepsilon}
\end{gathered}
$$

Differentiating this equation yields one more equation that will be useful:

$$
\mathrm{W}^{\prime}(\mathrm{u})=(1-\varepsilon \alpha) \mathrm{W}^{\prime}(\mathrm{u}+\varepsilon \delta \mathrm{u}+\varepsilon \alpha \tau)+\varepsilon \alpha \mathrm{W}^{\prime}(\mathrm{u}+\varepsilon \delta \mathrm{u}+\varepsilon \alpha \tau-\tau), \quad \forall \mathrm{u} \in\left[\mathrm{G}_{\varepsilon}, \mathrm{H}_{\varepsilon}\right] .
$$

Let us now derive $\mathrm{w}_{0}$ from $\mathrm{W}$ according to $\left(6^{\prime}\right)$. Because $\mathrm{W}$ is an increasing function, the constrained minimization in $\left(6^{\prime}\right)$ can be achieved by making $\mathrm{y}, \mathrm{s}, \mathrm{r}-\mathrm{z}$, and $\mathrm{r}$ as small as possible, with $\mathrm{y}=0, \mathrm{~s}=\mathrm{D}, \mathrm{r}-\mathrm{z}=\mathrm{D}$ and $\mathrm{r}=\mathrm{D}+\tau=\mathrm{G}$, so that $\left(6^{\prime}\right)$ becomes

$$
\mathrm{W}_{0}=\min _{\mathrm{p} \in[0,1]} \mathrm{p}[\mathrm{W}(\mathrm{D})+\varepsilon \beta \mathrm{L}]+(1-\mathrm{p})[(1-\varepsilon \alpha) \mathrm{W}(\mathrm{G})+\varepsilon \alpha \mathrm{W}(\mathrm{D})+\varepsilon \alpha \mathrm{L}+\varepsilon \gamma]
$$

Then, with $\mathrm{G}_{\varepsilon}=(\mathrm{G}-\varepsilon \alpha \tau) /(1+\varepsilon \delta)$, the difference between the bracketed terms here is:

$$
\begin{aligned}
{[(1-\varepsilon \alpha) W(G)+\varepsilon \alpha \mathrm{W}(\mathrm{G}-\tau)+\varepsilon(\alpha \mathrm{L}+\gamma)]-[\mathrm{W}(\mathrm{D})+\varepsilon \beta \mathrm{L}] } \\
=(1+\varepsilon \delta) \mathrm{W}\left(\mathrm{G}_{\varepsilon}\right)-[\mathrm{W}(\mathrm{D})+\varepsilon \beta \mathrm{L}] \\
=(1+\varepsilon \delta)\left(\mathrm{G}_{\varepsilon}-\mathrm{D}\right) \mathrm{W}^{\prime}(\mathrm{D})+\varepsilon \delta[\mathrm{W}(\mathrm{D})-\beta \mathrm{L} / \delta] \\
=(1-\mu)(\mathrm{G}-\varepsilon \alpha \tau-\mathrm{D})+\varepsilon \delta\left[\mathrm{W}(\mathrm{D})-\mathrm{DW}^{\prime}(\mathrm{D})-\beta \mathrm{L} / \delta\right]
\end{aligned}
$$

So in the HBC case when $\mu=1$, this difference is nonpositive (as the first term in the last line becomes 0 ); but in the SBC case when $\mu<1$, this difference is positive (as the last bracketed term on the last line becomes 0$)$. Thus, in the HBC case, the optimal policy in $\left(6^{\prime}\right)$ has $p=0$ and yields

$$
\mathrm{W}_{0}=(1-\varepsilon \alpha) \mathrm{W}(\mathrm{G})+\varepsilon \alpha \mathrm{W}(\mathrm{D})+\varepsilon \alpha \mathrm{L}+\varepsilon \gamma=(1+\varepsilon \delta) \mathrm{W}\left(\mathrm{G}_{\varepsilon}\right) \text { when } \mu=1 ;
$$

but in the SBC case, the optimal policy in $\left(6^{\prime}\right)$ has $\mathrm{p}=1$ and yields

$$
\mathrm{w}_{0}=\mathrm{W}(\mathrm{D})+\varepsilon \beta \mathrm{L} \text { when } \mu<1 \text {. }
$$

For any given $\mathrm{u}$, consider a Lagrangean relaxation of the minimization problem in ( $\left.7^{\prime}\right)$, where the promise-keeping constraint is added into the minimand with a multiplier $\lambda$. That is, consider the problem of minimizing the Lagrangean: 


$$
\begin{aligned}
\{\varepsilon y+ & \mathrm{qw}_{0}+\mathrm{p}[\mathrm{W}(\mathrm{s})+\varepsilon \beta \mathrm{L}]+ \\
& +(1-\mathrm{q}-\mathrm{p})[(1-\varepsilon \alpha) \mathrm{W}(\mathrm{r})+\varepsilon \alpha \mathrm{W}(\mathrm{r}-\mathrm{z})+\varepsilon \alpha \mathrm{L}+\varepsilon \gamma]\} /(1+\varepsilon \delta) \\
& +\lambda[(1+\varepsilon \delta) \mathrm{u}-\varepsilon \mathrm{y}-\mathrm{ps}-(1-\mathrm{q}-\mathrm{p})(\mathrm{r}-\varepsilon \alpha \mathrm{z})]
\end{aligned}
$$

subject to the constraints $\left(2^{\prime}\right)-\left(5^{\prime}\right)$ :

$$
\mathrm{z} \geq \tau, \quad \mathrm{r}-\mathrm{z} \geq \mathrm{D}, \mathrm{r} \leq \mathrm{H}, \mathrm{s} \leq \mathrm{H}, \mathrm{y} \geq 0, \mathrm{p} \geq 0, \mathrm{q} \geq 0, \mathrm{p}+\mathrm{q} \leq 1 .
$$

First consider $\mathrm{u}$ such that $\mathrm{G}_{\varepsilon} \leq \mathrm{u} \leq \mathrm{H}_{\varepsilon}$, and let the Lagrange multiplier be

$$
\lambda=\mathrm{W}^{\prime}(\mathrm{u}) /(1+\varepsilon \delta)=\left[(1-\varepsilon \alpha) \mathrm{W}^{\prime}(\mathrm{u}+\varepsilon \delta \mathrm{u}+\varepsilon \alpha \tau)+\varepsilon \alpha \mathrm{W}^{\prime}(\mathrm{u}+\varepsilon \delta \mathrm{u}+\varepsilon \alpha \tau-\tau)\right] /(1+\varepsilon \delta) .
$$

Then for any $\mathrm{p}$ and $\mathrm{q}$, the Lagrangean is minimized over $(\mathrm{y}, \mathrm{r}, \mathrm{z}, \mathrm{s})$ subject to $\left(2^{\prime}\right)-\left(5^{\prime}\right)$ by

$$
\mathrm{r}=\mathrm{u}+\varepsilon \delta \mathrm{u}+\varepsilon \alpha \tau, \mathrm{z}=\tau, \mathrm{y}=0, \mathrm{~s}=\mathrm{u} .
$$

(To verify this minimization, notice that the Lagrangean is convex in $(\mathrm{r}, \mathrm{z}, \mathrm{y}, \mathrm{s})$, and these values satisfy the first-order conditions for minimizing the Lagrangean subject to the linear constraints $\mathrm{z} \geq \tau$ and $\mathrm{y} \geq 0$. We use the fact that, by convexity, $\mathrm{W}^{\prime}(\mathrm{u})$ is increasing in $\mathrm{u}$ and is never greater than 1.) Then we get $\mathrm{r}-\varepsilon \alpha \mathrm{z}=\mathrm{u}+\varepsilon \delta \mathrm{u}$, and the Lagrangean reduces to

$$
\begin{aligned}
\left\{\mathrm{q} \mathrm{w}_{0}+\mathrm{p}[\mathrm{W}(\mathrm{u})+\varepsilon \beta \mathrm{L}]+(1-\mathrm{q}-\mathrm{p})(1+\varepsilon \delta) \mathrm{W}(\mathrm{u})+\right. \\
\left.+\mathrm{W}^{\prime}(\mathrm{u})[(1+\varepsilon \delta) \mathrm{u}-\mathrm{pu}-(1-\mathrm{q}-\mathrm{p})(\mathrm{u}+\varepsilon \delta \mathrm{u})]\right\} /(1+\varepsilon \delta) .
\end{aligned}
$$

Notice $W(u)-u W^{\prime}(u)$ is a decreasing function of $u$, because $W$ is convex and $u>0$. So the coefficient of $\mathrm{p}$ in the reduced Lagrangean is

$$
\begin{aligned}
\{\mathrm{W}(\mathrm{u})+ & \left.\varepsilon \beta \mathrm{L}-(1+\varepsilon \delta) \mathrm{W}(\mathrm{u})-\mathrm{W}^{\prime}(\mathrm{u}) \mathrm{u}+\mathrm{W}^{\prime}(\mathrm{u})(\mathrm{u}+\varepsilon \delta \mathrm{u})\right\} /(1+\varepsilon \delta) \\
& =\left\{\varepsilon \beta \mathrm{L}-\varepsilon \delta\left[\mathrm{W}(\mathrm{u})-\mathrm{uW}^{\prime}(\mathrm{u})\right]\right\} /(1+\varepsilon \delta) \\
& \geq \varepsilon \delta\left\{\beta \mathrm{L} / \delta-\left[\mathrm{W}(\mathrm{D})-\mathrm{DW}^{\prime}(\mathrm{D})\right]\right\} /(1+\varepsilon \delta) \geq 0 .
\end{aligned}
$$

Similarly, the coefficient of $q$ in the reduced Lagrangean is

$$
\left\{\mathrm{W}_{0}-(1+\varepsilon \delta)\left[\mathrm{W}(\mathrm{u})-\mathrm{uW}^{\prime}(\mathrm{u})\right]\right\} /(1+\varepsilon \delta),
$$

which in the $\mathrm{HBC}$ case (where $\mathrm{W}$ is constant below $\mathrm{G}_{\varepsilon}$ ) becomes

$$
\mathrm{W}\left(\mathrm{G}_{\varepsilon}\right)-\left[\mathrm{W}(\mathrm{u})-\mathrm{uW}^{\prime}(\mathrm{u})\right] \geq \mathrm{W}\left(\mathrm{G}_{\varepsilon}\right)-\left[\mathrm{W}(\mathrm{D})-\mathrm{DW}^{\prime}(\mathrm{D})\right]=0,
$$

and which in the SBC case becomes

$$
\begin{aligned}
\{[\mathrm{W}(\mathrm{D}) & \left.+\varepsilon \beta \mathrm{L}]-(1+\varepsilon \delta)\left[\mathrm{W}(\mathrm{u})-\mathrm{uW}^{\prime}(\mathrm{u})\right]\right\} /(1+\varepsilon \delta) \\
\geq & \left\{[\mathrm{W}(\mathrm{D})+\varepsilon \beta \mathrm{L}]-(1+\varepsilon \delta)\left[\mathrm{W}(\mathrm{D})-\mathrm{DW}^{\prime}(\mathrm{D})\right]\right\} /(1+\varepsilon \delta) \\
= & \left\{[\mathrm{W}(\mathrm{D})-\beta \mathrm{L} / \delta]-(1+\varepsilon \delta)\left[\mathrm{W}(\mathrm{D})-\mathrm{DW}^{\prime}(\mathrm{D})-\beta \mathrm{L} / \delta\right]\right\} /(1+\varepsilon \delta) \\
= & \mathrm{DW}^{\prime}(\mathrm{D}) /(1+\varepsilon \delta) \geq 0 .
\end{aligned}
$$

Thus, as both coefficients are nonnegative, the Lagrangean is minimized by $p=0$ and $q=0$. As this solution also satisfies promise-keeping constraint $\left(1^{\prime}\right)$ with equality, it is also optimal for the 
original problem $\left(7^{\prime}\right)$. With this optimal solution, the minimum on the right side of $\left(7^{\prime}\right)$ becomes

$$
\begin{aligned}
& \{[(1-\varepsilon \alpha) \mathrm{W}(\mathrm{u}+\varepsilon \delta \mathrm{u}+\varepsilon \alpha \tau)+\varepsilon \alpha \mathrm{W}(\mathrm{u}+\varepsilon \delta \mathrm{u}+\varepsilon \alpha \tau-\tau)+\varepsilon(\alpha \mathrm{L}+\gamma)]\} /(1+\varepsilon \delta) \\
& =\mathrm{W}(\mathrm{u}),
\end{aligned}
$$

and so equation $\left(7^{\prime}\right)$ is verified for all $\mathrm{u}$ in $\left[\mathrm{G}_{\varepsilon}, \mathrm{H}_{\varepsilon}\right]$.

Next, consider $\mathrm{u}$ such that $\mathrm{u}>\mathrm{H}_{\varepsilon}$, and let the Lagrange multiplier be $\lambda=1 /(1+\varepsilon \delta)$. Then the Lagrangean becomes

$$
\begin{aligned}
\{\varepsilon y+ & \mathrm{qw}_{0}+\mathrm{p}[\mathrm{W}(\mathrm{s})+\varepsilon \beta \mathrm{L}]+(1-\mathrm{q}-\mathrm{p})[(1-\varepsilon \alpha) \mathrm{W}(\mathrm{r})+\varepsilon \alpha \mathrm{W}(\mathrm{r}-\mathrm{z})+\varepsilon(\alpha \mathrm{L}+\gamma)]+ \\
& +[(1+\varepsilon \delta) \mathrm{u}-\varepsilon \mathrm{y}-\mathrm{ps}-(1-\mathrm{q}-\mathrm{p})(\mathrm{r}-\varepsilon \alpha \mathrm{z})]\} /(1+\varepsilon \delta) .
\end{aligned}
$$

By first order conditions, using the fact that $\mathrm{W}^{\prime}$ is never more than 1 , the minimization of this Lagrangean subject to $\mathrm{r} \leq \mathrm{H}, \mathrm{s} \leq \mathrm{H}$ and $\mathrm{z} \geq \tau$ can be achieved by letting

$\mathrm{s}=\mathrm{H}, \mathrm{r}=\mathrm{H}$, and $\mathrm{z}=\tau$.

The coefficient of $y$ in this Lagrangean is zero, and so we can minimize the Lagrangean by letting

$$
\varepsilon y=(1+\varepsilon \delta) \mathrm{u}-(\mathrm{H}-\varepsilon \alpha \tau),
$$

which is nonnegative because $\mathrm{u} \geq \mathrm{H}_{\varepsilon}=(\mathrm{H}-\varepsilon \alpha \tau) /(1+\varepsilon \delta)$. Then the Lagrangean reduces to

$$
\begin{aligned}
\left\{\mathrm{qw}_{0}+\mathrm{p}[\mathrm{W}(\mathrm{H})+\varepsilon \beta \mathrm{L}]+(1-\mathrm{q}-\mathrm{p})(1+\varepsilon \delta) \mathrm{W}\left(\mathrm{H}_{\varepsilon}\right)+\right. \\
+[(1+\varepsilon \delta) \mathrm{u}-\mathrm{pH}-(1-\mathrm{q}-\mathrm{p})(\mathrm{H}-\varepsilon \alpha \tau)]\} /(1+\varepsilon \delta) \\
=\left\{\mathrm{qw}_{0}+\mathrm{p}[\mathrm{W}(\mathrm{H})+\varepsilon \beta \mathrm{L}]+(1-\mathrm{q}-\mathrm{p})(1+\varepsilon \delta)\left[\mathrm{W}(\mathrm{H})+\left(\mathrm{H}_{\varepsilon}-\mathrm{H}\right)\right]+\right. \\
+[(1+\varepsilon \delta) \mathrm{u}+(1-\mathrm{q}-\mathrm{p}) \varepsilon \alpha \tau-(1-\mathrm{q}) \mathrm{H}]\} /(1+\varepsilon \delta) .
\end{aligned}
$$

(Recall that $\mathrm{W}^{\prime}(\mathrm{u})=1$ when $\mathrm{u}>\mathrm{H}_{\varepsilon}$.) So the coefficient of $\mathrm{p}$ in the reduced Lagrangean is

$$
\begin{aligned}
\{\mathrm{W}(\mathrm{H}) & +\varepsilon \beta \mathrm{L}-(1+\varepsilon \delta) \mathrm{W}(\mathrm{H})+\varepsilon(\delta \mathrm{H}+\alpha \tau)-\varepsilon \alpha \tau\} /(1+\varepsilon \delta) \\
& =\varepsilon \delta\left\{\beta \mathrm{L} / \delta-\left[\mathrm{W}(\mathrm{H})-\mathrm{HW}^{\prime}(\mathrm{H})\right]\right\} /(1+\varepsilon \delta) \\
& \geq \varepsilon \delta\left\{\beta \mathrm{L} / \delta-\left[\mathrm{W}(\mathrm{D})-\mathrm{DW}^{\prime}(\mathrm{D})\right]\right\} /(1+\varepsilon \delta) \geq 0 .
\end{aligned}
$$

Similarly, the coefficient of $\mathrm{q}$ in the reduced Lagrangean is

$$
\begin{aligned}
& \left\{\mathrm{w}_{0}-(1+\varepsilon \delta) \mathrm{W}(\mathrm{H})+\varepsilon(\delta \mathrm{H}+\alpha \tau)-\varepsilon \alpha \tau+\mathrm{H}\right\} /(1+\varepsilon \delta), \\
& =\left\{\mathrm{w}_{0}-(1+\varepsilon \delta)\left[\mathrm{W}(\mathrm{H})-\mathrm{HW}^{\prime}(\mathrm{H})\right]\right\} /(1+\varepsilon \delta),
\end{aligned}
$$

which is also nonnegative (as argued in the previous paragraph). Thus, as both coefficients are nonnegative, the Lagrangean is again minimized by $\mathrm{p}=0$ and $\mathrm{q}=0$. As this solution also satisfies promise-keeping constraint with equality, it is also optimal for the original problem on the righthand side of $\left(7^{\prime}\right)$. With this solution, the minimum on the right-hand side of $\left(7^{\prime}\right)$ becomes

$$
\begin{gathered}
\{(1+\varepsilon \delta) \mathrm{u}-(\mathrm{H}-\varepsilon \alpha \tau)+[(1-\varepsilon \alpha) \mathrm{W}(\mathrm{H})+\varepsilon \alpha \mathrm{W}(\mathrm{H}-\tau)+\varepsilon \alpha \mathrm{L}+\varepsilon \gamma]\} /(1+\varepsilon \delta) \\
=\mathrm{u}-\mathrm{H}_{\varepsilon}+\mathrm{W}\left(\mathrm{H}_{\varepsilon}\right)=\mathrm{W}(\mathrm{u}),
\end{gathered}
$$


and so equation $\left(7^{\prime}\right)$ is verified for $\mathrm{u}>\mathrm{H}_{\varepsilon}$.

Finally, consider $u$ such that $u<G_{\varepsilon}$, and let the Lagrange multiplier be $\lambda=(1-\mu) /(1+\varepsilon \delta)$. In this case, the Lagrangean becomes

$$
\begin{aligned}
& \left\{\varepsilon y+\mathrm{qw}_{0}+\mathrm{p}[\mathrm{W}(\mathrm{s})+\varepsilon \beta \mathrm{L}]+(1-\mathrm{q}-\mathrm{p})[(1-\varepsilon \alpha) \mathrm{W}(\mathrm{r})+\varepsilon \alpha \mathrm{W}(\mathrm{r}-\mathrm{z})+\varepsilon(\alpha \mathrm{L}+\gamma)]+\right. \\
& \quad+(1-\mu)[(1+\varepsilon \delta) \mathrm{u}-\varepsilon \mathrm{y}-\mathrm{ps}-(1-\mathrm{q}-\mathrm{p})(1-\varepsilon \alpha) \mathrm{r}-(1-\mathrm{q}-\mathrm{p}) \varepsilon \alpha(\mathrm{r}-\mathrm{z})]\} /(1+\varepsilon \delta) .
\end{aligned}
$$

Using the facts that $\mu>0$, and $W^{\prime}$ is never less than $1-\mu$, but $W^{\prime}(s)=1-\mu$ if $s<G_{\varepsilon}$, we find that this Lagrangean can be minimized over (y,r,z,s) subject to $\mathrm{y} \geq 0, \mathrm{r}-\mathrm{z} \geq \mathrm{D}$, and $\mathrm{z} \geq \tau$ by choosing

$$
\mathrm{y}=0, \mathrm{r}-\mathrm{z}=\mathrm{D}, \mathrm{z}=\tau, \mathrm{s}=\min \left\{\mathrm{u}+\varepsilon \delta, \mathrm{G}_{\varepsilon}\right\} .
$$

With these optimal values, the Lagrangean reduces to

$$
\begin{aligned}
& \left\{\mathrm{qw}_{0}+\mathrm{p}[\mathrm{W}(\mathrm{s})+\varepsilon \beta \mathrm{L}]+(1-\mathrm{q}-\mathrm{p})(1+\varepsilon \delta) \mathrm{W}\left(\mathrm{G}_{\varepsilon}\right)+\right. \\
& \quad+(1-\mu)[(1+\varepsilon \delta) \mathrm{u}-\mathrm{ps}-(1-\mathrm{q}-\mathrm{p})(\mathrm{G}-\varepsilon \alpha \tau)]\} /(1+\varepsilon \delta) .
\end{aligned}
$$

But $W\left(G_{\varepsilon}\right)=W(D)+(1-\mu)\left(G_{\varepsilon}-D\right)$, because the function $W$ has slope $1-\mu$ between $D$ and $G_{\varepsilon}$. So the coefficient of $q$ in the reduced Lagrangean is

$$
\begin{gathered}
\left\{\mathrm{W}_{0}-(1+\varepsilon \delta) \mathrm{W}(\mathrm{D})-(1-\mu)(\mathrm{G}-\varepsilon \alpha \tau-\mathrm{D}-\varepsilon \delta \mathrm{D})+(1-\mu)(\mathrm{G}-\varepsilon \alpha \tau)\right\} /(1+\varepsilon \delta) \\
=\left\{\mathrm{w}_{0}-(1+\varepsilon \delta)\left[\mathrm{W}(\mathrm{D})-\mathrm{DW}^{\prime}(\mathrm{D})\right]\right\} /(1+\varepsilon \delta)
\end{gathered}
$$

which is nonnegative by the same argument that we applied above. The coefficient of $p$ in the reduced Lagrangean is

$$
\begin{aligned}
\{\mathrm{W}(\mathrm{s}) & \left.+\varepsilon \beta \mathrm{L}-(1+\varepsilon \delta)\left[\mathrm{W}(\mathrm{s})+(1-\mu)\left(\mathrm{G}_{\varepsilon}-\mathrm{s}\right)\right]+(1-\mu)(\mathrm{G}-\varepsilon \alpha \tau-\mathrm{s})\right\} /(1+\varepsilon \delta) \\
& =\{\varepsilon \beta \mathrm{L}-\varepsilon \delta \mathrm{W}(\mathrm{s})-(1-\mu)(\mathrm{G}-\varepsilon \alpha \tau-\mathrm{s}-\varepsilon \delta \mathrm{s}-\mathrm{G}+\varepsilon \alpha \tau+\mathrm{s})\} /(1+\varepsilon \delta) \\
& =\varepsilon \delta\left\{\beta \mathrm{L} / \delta-\left[\mathrm{W}(\mathrm{s})-\mathrm{sW}^{\prime}(\mathrm{s})\right]\right\} /(1+\varepsilon \delta)
\end{aligned}
$$

which is nonnegative in the $\mathrm{HBC}$ case and (with $\mathrm{s} \leq \mathrm{G}_{\varepsilon}$ ) is zero in the SBC case. So in the SBC case, the Lagrangean can be minimized by setting

$$
\mathrm{q}=0 \text { and } \mathrm{p}=\left(\mathrm{G}_{\varepsilon}-\mathrm{u}\right) /\left[\mathrm{G}_{\varepsilon}-\mathrm{s} /(1+\varepsilon \delta)\right],
$$

so that the promise-keeping constraint $\left(1^{\prime}\right)$ is satisfied with equality. This SBC solution yields

$$
\begin{aligned}
& \mathrm{s}=\mathrm{u}+\varepsilon \delta \mathrm{u} \text { and } \mathrm{p}=1 \text { when } \mathrm{u} \leq \mathrm{G}_{\varepsilon} /(1+\varepsilon \delta), \\
& \mathrm{s}=\mathrm{G}_{\varepsilon} \text { and } \mathrm{p}=\left(1-\mathrm{u} / \mathrm{G}_{\varepsilon}\right)[1+1 /(\varepsilon \delta)] \text { when } \mathrm{G}_{\varepsilon} /(1+\varepsilon \delta)<\mathrm{u}<\mathrm{G}_{\varepsilon}
\end{aligned}
$$

and the minimum on the right-hand side of $\left(7^{\prime}\right)$ becomes

$$
\begin{aligned}
\{\mathrm{p}[\mathrm{W}(\mathrm{s}) & \left.+\varepsilon \beta \mathrm{L}]+(1-\mathrm{p})(1+\varepsilon \delta) \mathrm{W}\left(\mathrm{G}_{\varepsilon}\right)\right\} /(1+\varepsilon \delta) \\
= & \left\{\mathrm{p}[\beta \mathrm{L} / \delta+(1-\mu) \mathrm{s}+\varepsilon \beta \mathrm{L}]+(1-\mathrm{p})(1+\varepsilon \delta)\left[\beta \mathrm{L} / \delta+(1-\mu) \mathrm{G}_{\varepsilon}\right]\right\} /(1+\varepsilon \delta) \\
= & \beta \mathrm{L} / \delta+(1-\mu)\left[\mathrm{ps} /(1+\varepsilon \delta)+(1-\mathrm{p}) \mathrm{G}_{\varepsilon}\right] \\
= & \beta \mathrm{L} / \delta+(1-\mu) \mathrm{u}=\mathrm{W}(\mathrm{u})
\end{aligned}
$$


So equation $\left(7^{\prime}\right)$ is verified for the $\mathrm{SBC}$ case with $\mathrm{u}<\mathrm{G}_{\varepsilon}$. On the other hand, in the HBC case, this Lagrangean is minimized by setting

$$
\mathrm{q}=0 \text { and } \mathrm{p}=0 .
$$

Then the promise-keeping constraint has slack, but its Lagrange multiplier is $1-\mu=0$. So these values solve the original minimization problem on the right-hand side of $\left(7^{\prime}\right)$ for this $u<G_{\varepsilon}$, and equation $\left(7^{\prime}\right)$ is satisfied because

$$
[(1-\varepsilon \alpha) \mathrm{W}(\mathrm{G})+\varepsilon \alpha \mathrm{W}(\mathrm{D})+\varepsilon(\alpha \mathrm{L}+\gamma)] /(1+\varepsilon \delta)=\mathrm{W}\left(\mathrm{G}_{\varepsilon}\right)=\mathrm{W}(\mathrm{u})
$$

in the $\mathrm{HBC}$ case where $\mathrm{W}^{\prime}(\mathrm{u})=0$ for $\mathrm{u}<\mathrm{G}_{\varepsilon}$.

Thus we have proven that the $\mathrm{W}$ function that is computed from $\mathrm{V}$ according to the theorem satisfies the recursive optimality equations $\left(7^{\prime}\right)$ with the optimal policies that are specified in the theorem.

Q.E.D.

Finally, we can describe how the solution in Theorem 6 would change with $\mathrm{K}>0$. Let $\mathrm{V}_{0}(\mathrm{u})$ denote the value of $\mathrm{V}(\mathrm{u})$ in Theorem 1 with $\mathrm{K}=0$ but with all other parameters are as given; that is $\mathrm{V}_{0}(\mathrm{u})$ is the expected total cost of wages under the HBC plan. For the SBC plan, expected net cost with $\mathrm{K}>0$ would be the same as with $\mathrm{K}=0$ once a governor has been appointed, and so

$$
\mathrm{W}_{\mathrm{SBC}}(\mathrm{u})=\mathrm{u}+\left(\mathrm{V}_{0}(\mathrm{u})-\mathrm{u}\right)(\beta \mathrm{L}-\alpha \mathrm{L}-\gamma) /\left(\delta \mathrm{V}_{0}(0)\right)+(\alpha \mathrm{L}+\gamma) / \delta, \quad \forall \mathrm{u} \geq \mathrm{D},
$$

but now $\mathrm{W}_{\mathrm{SBC}}(0)=\mathrm{W}_{\mathrm{SBC}}(\mathrm{D})-\mathrm{K}$. The high-effort $\mathrm{HBC}$ plan has a new wrinkle, however. When we allow that a governor can trust the prince even with credit as low as $\mathrm{D}$, then a new governor can be asked to pay $\mathrm{K}$ for appointment with credit $\mathrm{D}$, and then, after a short period of time, the new governor can be either promoted to credit $\mathrm{G}$, with probability $\mathrm{D} / \mathrm{G}$, or else dismissed. High effort cannot be demanded until the governor is promoted to G, but this low-effort period could be made arbitrarily short. With such randomization for new appointments, any dismissal would be quickly followed by the prince collecting $\mathrm{K}$ from a random number of new governors that has expected value G/D. So we can implement a modified HBC plan that differs from the optimal policy in Theorem 1 only in that, after any crisis-penalty dismissal, the prince can resell the governor's office for expected revenue KG/D instead of K, and so (applying Theorem 3) the expected net cost becomes

$$
\mathrm{W}_{\mathrm{HBC}}(\mathrm{u})=\mathrm{u}+\left(\mathrm{V}_{0}(\mathrm{u})-\mathrm{u}\right)(1-\mathrm{K} / \mathrm{D})+(\alpha \mathrm{L}+\gamma) / \delta, \forall \mathrm{u} \geq 0 .
$$

The SBC plan is optimal when $(\beta \mathrm{L}-\alpha \mathrm{L}-\gamma) / \delta<(1-\mathrm{K} / \mathrm{D}) \mathrm{V}_{0}(0)$, and otherwise the modified HBC plan is optimal. 


\section{References}

Dilip Abreu, Paul Milgrom, and David Pearce, "Information and timing in repeated partnerships," Econometrica 59(6):1713-1733 (1991).

Dilip Abreu, David Pearce, and Ennio Stacchetti, "Toward a theory of discounted repeated games with imperfect monitoring," Econometrica 58:1041-1063 (1990).

Daron Acemoglu, Michael Golosov, and Aleh Tsyvinski, "Political economy of mechanisms," Econometrica 76(3):619-641 (2008).

Daron Acemoglu, James Robinson, and Thierry Verdier, "Kleptocracy and divide-and-rule: a model of personal rule," Journal of the European Economic Association 2(2-3):162-192 (2004).

George A. Akerlof and Lawrence F. Katz, "Workers' trust funds and the logic of wage profiles," Quarterly Journal of Economics 104:525-536 (1989).

Robert Barro, "Control of politicians," Public Choice 14:19-42 (1973).

Gary Becker, George Stigler, "Law enforcement, malfeasance, and compensation of enforcers," Journal of Legal Studies 3:1-18 (1974).

Gary Beckman, "The Hittite assembly," Journal of the American Oriental Society 102:435-442 (1982).

Timothy Besley, Principled Agents: The Political Economy of Good Government (Oxford University Press, 2006).

Bruno Biais, Thomas Mariotti, Jean-Charles Rochet, Stephane Villeneuve, "Large risks, limited liability, and dynamic moral hazard," Econometrica 78(1):73-118 (2010).

Clive Bull, "The existence of self-enforcing implicit contracts," Quarterly Journal of Economics 102(1):147-160 (1987).

Peter Coss, The Origins of the English Gentry (Cambridge, 2005).

Alexandre Debs, "Economic theories of dictatorship," Economics of Peace and Security Journal 5(1):20-25 (2010).

Georgy Egorov and Konstantin Sonin, "Dictators and their viziers," Journal of European Economic Association 9(5):903-930 (2011).

John Ferejohn, "Incumbent Performance and Electoral Control." Public Choice 50: 5-26 (1986). Richard FitzNigel, Dialogus de Scaccario (Dialogue of the Exchequer), translated by 
Charles Johnson (Oxford, 1983).

Yuk-Fai Fong and Jin Li, "Relational contracts, efficiency wages, and employment dynamics," Northwestern University working paper (2012).

Janos Kornai, Eric Maskin, and Gerard Roland, "Understanding the soft budget constraint," Journal of Economic Literature (Dec 2003), 41:1095-1136.

Edward P. Lazear, "Agency, earnings profiles, productivity, and hours restrictions," American Economic Review 71(4):606-620 (1981).

Jonathan Levin, "Relational incentive contracts," American Economic Review 93(3):835-857 (2003).

W. Bentley MacLeod, "Reputations, relationships, and contract enforcement," Journal of Economic Literature 45(3):595-628 (2007).

Frederick W. Mote, Imperial China 900-1800, (Harvard, 1999).

Roger Myerson, "The autocrat's credibility problem and foundations of the constitutional state," American Political Science Review 102:125-139 (2008).

Gerard Padro-i-Miquel, "Control of politicians in divided societies," Review of Economic Studies 74(4):1259-1274 (2007).

Gerard Padro-i-Miquel and Pierre Yared, "The political economy of indirect control," Quarterly Journal of Economics 127(2):947-1015 (2012).

Debraj Ray, "The time structure of self-enforcing agreements," Econometrica 70(2):547-582 (2002).

Yuliy Sannikov and Andrzej Skrzypacz, "The role of information in repeated games with frequent actions," Econometrica 78(3):847-882 (2010).

Carl Shapiro and Joseph E. Stiglitz, 'Equilibrium unemployment as a worker disciplinary device," American Economic Review 74:433-444 (1984).

Jonathan P. Thomas and Tim Worrall, "Dynamic relational contracts with credit constraints," University of Manchester working paper (2010).

Theo van den Hout, "The Proclamation of Telipinu," in The Context of Scripture, I, edited by William W. Hallo (Brill, 1997), pages 194-198.

W. L. Warren, Henry II, U. California Press (1973).

John Y. Zhu, "Optimal contracts with shirking," Review of Economic Studies 80(2):812-839 (2013). 


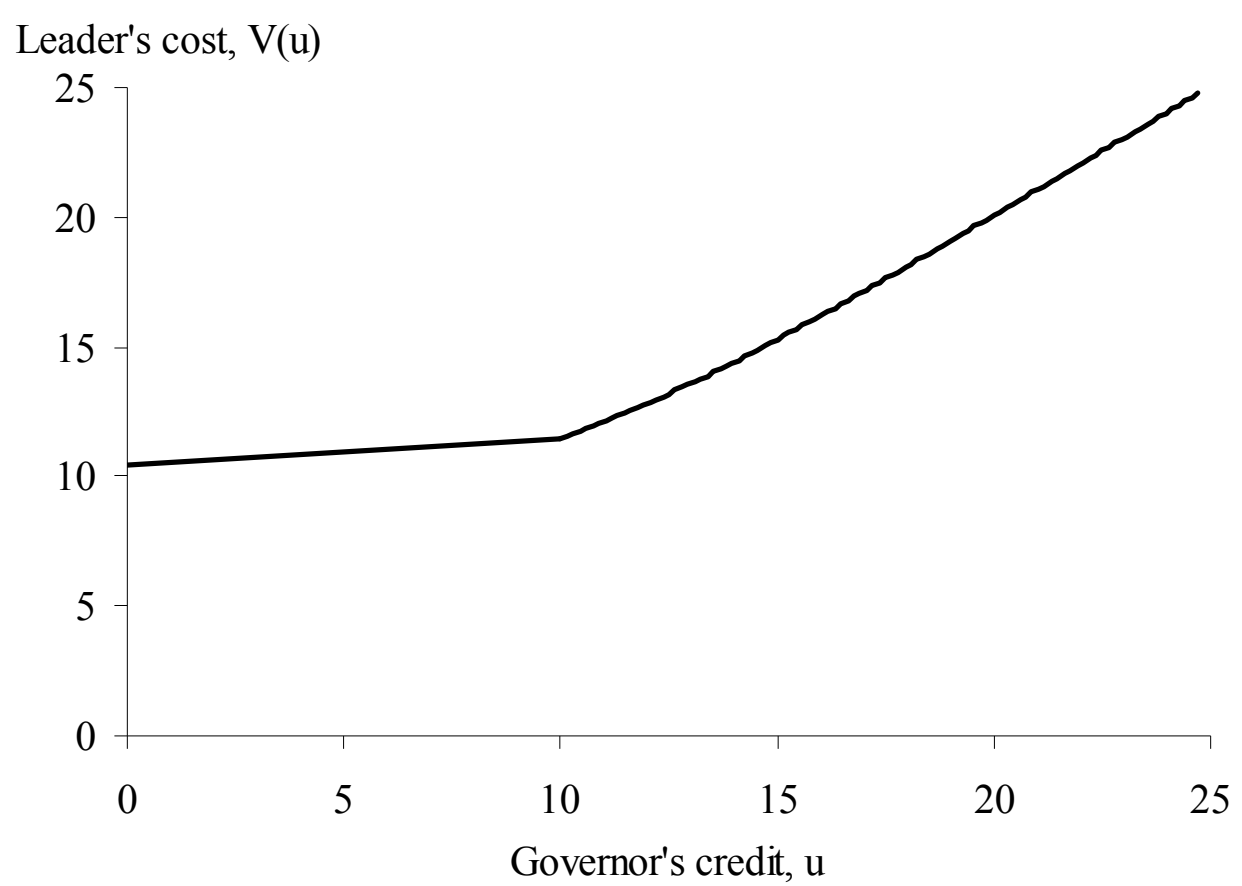

Figure 1. The leader's expected cost as a function of the credit owed to the governor, for an example with $\alpha=0.1, \beta=0.3, \delta=0.05, \gamma=1, D=5, K=1, H=25$.

Leader's cost, $\mathrm{V}(\mathrm{G})-\mathrm{K}$

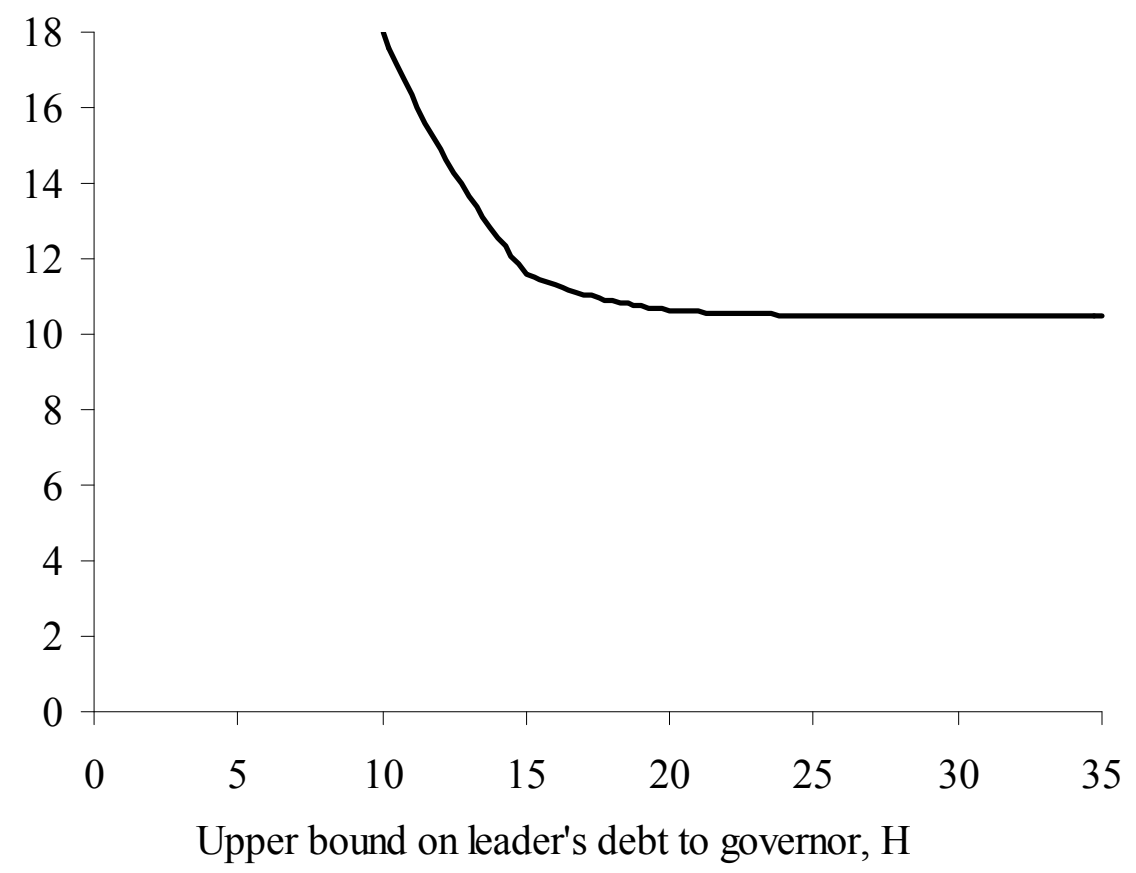

Figure 2. The leader's expected cost when appointing a new governor, as a function of the credit bound $\mathrm{H}$, when $\alpha=0.1, \beta=0.3, \gamma=1, \mathrm{D}=5, \mathrm{~K}=1$. 


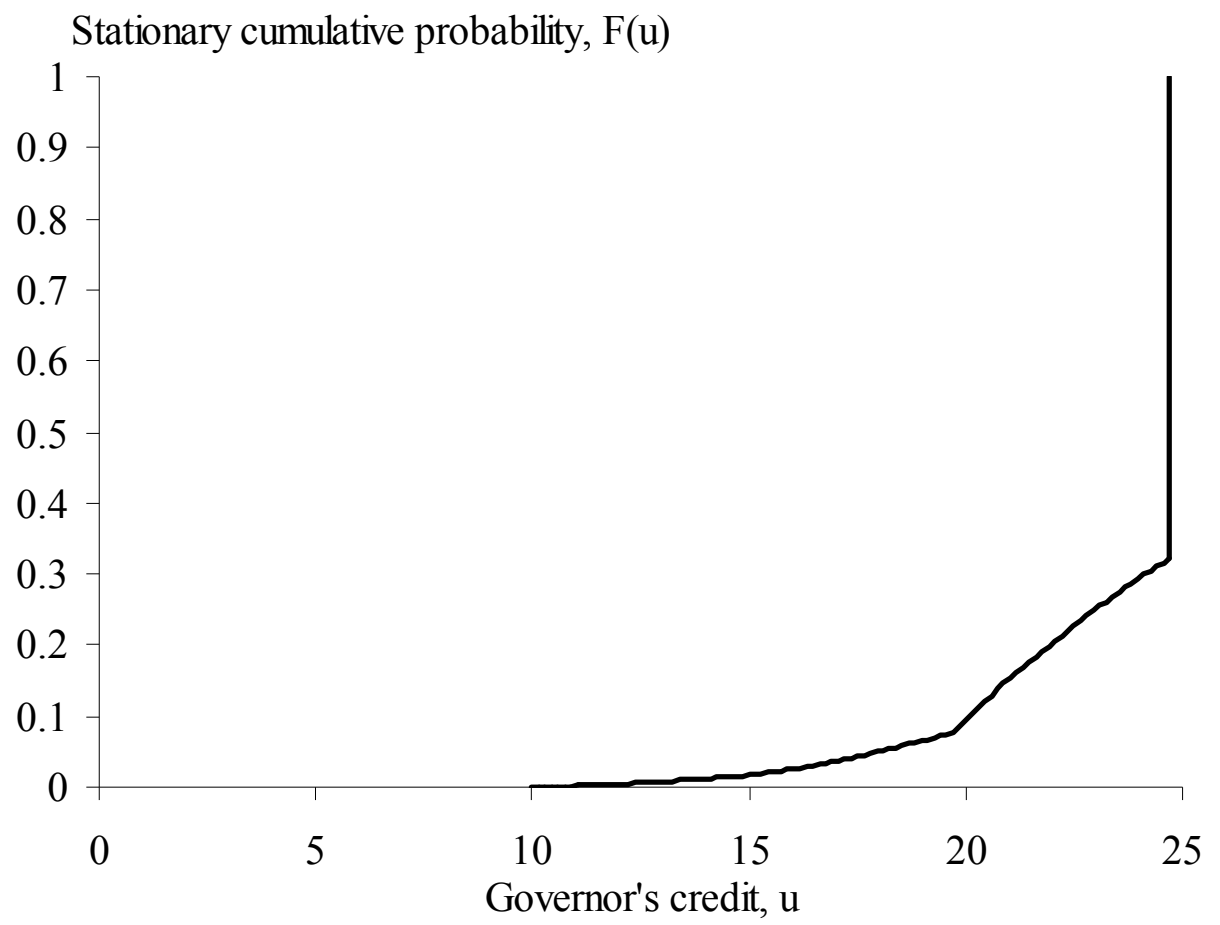

Figure 3. The stationary probability distribution of governors' credit, with $\alpha=0.1, \beta=0.3, \delta=0.05, \gamma=1, D=5, K=1, H=25$.

$\mathrm{H}$, trust bound

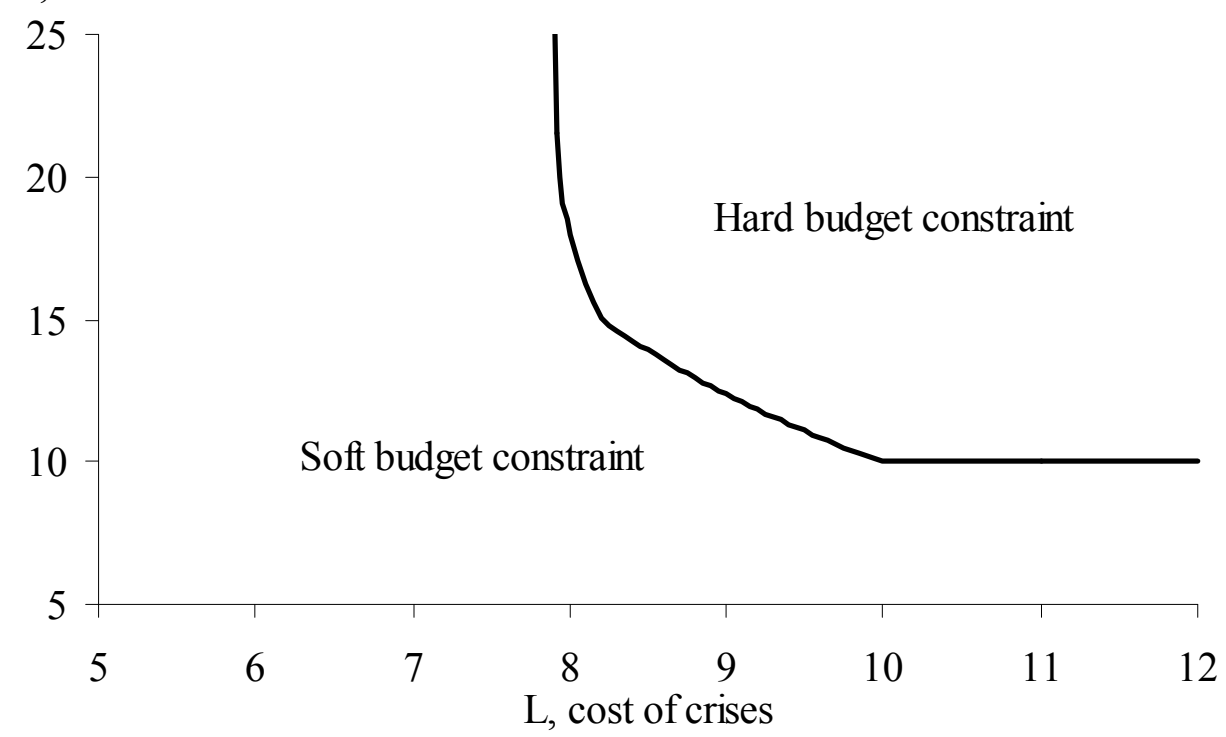

Figure 4. Optimality of incentive plans with hard or soft budget constraints, with $\alpha=0.1, \beta=0.3, \delta=0.05, \gamma=1, D=5, K=0$. 